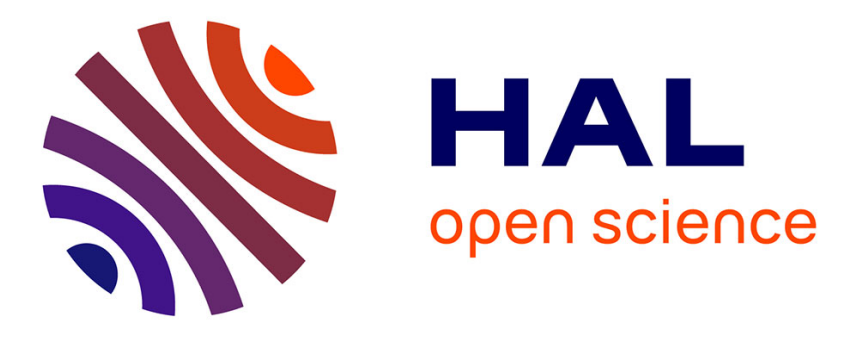

\title{
NIR-persistent luminescent nanoparticles for bioimaging, principle and perspectives
}

Bruno Viana, Cyrille Richard, Victor Castaing, Estelle Glais, Morgane Pellerin, Jianhua Liu, Corinne Chanéac

\section{- To cite this version:}

Bruno Viana, Cyrille Richard, Victor Castaing, Estelle Glais, Morgane Pellerin, et al.. NIR-persistent luminescent nanoparticles for bioimaging, principle and perspectives. Near Infrared Emitting Nanoparticles for Bioimaging Applications, 2020, 10.1007/978-3-030-32036-2_8 . hal-03023691

\section{HAL Id: hal-03023691 \\ https://hal.science/hal-03023691}

Submitted on 25 Nov 2020

HAL is a multi-disciplinary open access archive for the deposit and dissemination of scientific research documents, whether they are published or not. The documents may come from teaching and research institutions in France or abroad, or from public or private research centers.
L'archive ouverte pluridisciplinaire HAL, est destinée au dépôt et à la diffusion de documents scientifiques de niveau recherche, publiés ou non, émanant des établissements d'enseignement et de recherche français ou étrangers, des laboratoires publics ou privés. 


\title{
NIR-persistent luminescent nanoparticles for bio- imaging, principle and perspectives
}

\author{
Bruno Viana $^{\mathrm{a}}$, Cyrille Richard ${ }^{\mathrm{b}}$, Victor Castaing ${ }^{\mathrm{a}}$, Estelle Glais ${ }^{\mathrm{a}, \mathrm{c}}$, Morgane \\ Pellerin $^{\mathrm{a}, \mathrm{c}}$, Jianhua Liu ${ }^{\mathrm{b}}$, Corinne Chanéac ${ }^{\mathrm{c}}$ \\ ${ }^{a}$ Chimie ParisTech, PSL University, CNRS UMR 8247, Institut de Recherche de \\ Chimie Paris, 75005 Paris, France. \\ ${ }^{\mathrm{b}}$ Unité de Technologies Chimiques et Biologiques pour la Santé, CNRS UMR \\ 8258; Inserm U 1022; Université Paris Descartes, Sorbonne Paris Cité, Faculté des \\ Sciences Pharmaceutiques et Biologiques, 75006 Paris, France. \\ C. Laboratoire de Chimie de la Matière Condensée de Paris, CNRS UMR 7574 \\ Sorbonne Université, 75005 Paris France
}

\begin{abstract}
The development of nanoparticles for NIR imaging and diagnostics is an area of considerable interest. Among the different imaging modalities, optics emerged has an interesting technique since it is a non-invasive, cheap imaging technique allowing real time imaging. In-vitro, this technique is very useful, however in-vivo fluorescence imaging suffers from suboptimal signal-to-noise ratio, which is caused by the strong tissue autofluorescence under constant external excitation. To address this limitation, novel types of optical nanoprobes are actually being developed in the deep red/near infrared (NIR) range and among them, persistent luminescence nanoparticles (PLNPs), with long lasting near-infrared luminescence capability. These NPs allow optical imaging to be performed in an excitation-free and consequently autofluorescence-free manner. This chapter will first introduce the physical phenomenon associated to the long luminescence delay of such nanoprobes, from minutes to hours after ceasing the excitation, and will then highlight the tools used in physico-chemistry laboratories to characterize these nanoparticles with a focus on the $\mathrm{ZnGa}_{2} \mathrm{O}_{4}$ nanoparticles which are widely studied over the world. Then their biocompatibility will be mentioned and finally the evaluation in term of new advances for in-vivo bioimaging theranostics nanoprobes will be presented. We will conclude this chapter by envisioning perspectives for such nanomaterials.
\end{abstract}

Keywords : Persistent luminescence, nanoparticles, deep-red and NIR, imaging, therapy and theranostics. 


\section{Introduction}

Since the discovery of $\mathrm{SrAl}_{2} \mathrm{O}_{4}: \mathrm{Eu}^{2+}$, $\mathrm{Dy}^{3+}$ long persistent luminescence (PersL) by Matsuzawa et al. more than 20 years ago ${ }^{1}$, many persistent phosphors have been developed and studied. In the past decade, visible persistent phosphors based on sulfides, aluminates, gallates, and silicates hosts doped with various active ions have been developed ${ }^{2}$. Several compounds with sufficiently strong and long-lasting $(>10 \mathrm{~h})$ persistent luminescence properties in the green and blue ranges have already been commercialized and widely used in various applications, such as security and emergency route signs, dials and displays. More recently, persistent phosphors in the deep red emission range at nanometric scale have been proposed for in-vivo bio-imaging ${ }^{3}$. Optical imaging is highly complementary to other imaging methods, such as X-rays or magnetic resonance imaging, in particular due to its potential for data acquisition at high speeds. It allows the visualization of dynamic biological processes, events related to physiology and disease progression ${ }^{4}$. For that purpose, fluorescent probes enable the study of biological processes in great detail ${ }^{5}$. Among these probes, semiconductor quantum dots (QDs) exhibiting fluorescence optical properties have emerged as a class of nanoparticles for bioimaging and diagnostics. The possibility to detect and diagnose cancer or other human diseases at earlier stages than with current imaging methods caused a drastic increase of interest in nanoimaging technology. A non-invasive very cheap imaging technique, which is comfortable, portable, highly sensitive and that allows real-time imaging is still to be developed. The field of biomedical optics has matured rapidly during the last ten years, and is expected to continue its maturation in the next years. It provides a rapid, immediate (real-time dynamics) and cheap method for diagnosis. However, in spite of these great advantages, biomedical optics is limited because photons are scattered and absorbed by the tissues. The penetration depth of photons inside a tissue depends strongly on the type of tissue ${ }^{6}$, but most importantly, it depends on the wavelength $(\lambda)$ of the photons used. Scattering drastically decreases when $\lambda$ increases in the so-call tissue transparency window ${ }^{7}$ (see in figure 1 that mainly the red and near-infrared photons can go through living tissues). In-vivo imaging of exogenous fluorescent probes that target diseased tissues has also shown promising results in clinical settings, such as the early detection of breast cancer, the outlining of tumor margins during surgery and endoscopic diagnosis of cancer micrometastasis. However, the method is limited by tissue attenuation (scattering and absorption of the excitation or the emission light) and by tissue autofluorescence ${ }^{8}$. To minimize tissue attenuation effects, researchers have been concentrated on near-infrared (NIR) fluorophores that are excited and emit in the spectral window between wavelengths of 650 
$950 \mathrm{~nm}$. However, tissue autofluorescence still produces a substantial background signal in this spectral range that severely limits the quality of images, especially when very low concentrations of the fluorescent probe accumulate at the target site ${ }^{9}$.

Persistent luminescence phosphors are materials able to store optical energy and release it gradually by photon emission. This particular property is linked to the presence of trapping levels located in the forbidden gap of the material (see figure 1) ${ }^{2,10}$. Optical excitation of these materials leads to photoluminescence (PL) but can also induce charge trapping ${ }^{11}$. The trapped charges (electrons, holes) can then slowly be released following thermal stimulation, leading to their recombination at emitting centers followed by light emission for a long time (typically from minutes to hours ${ }^{1,12}$ ) after stopping the irradiation. For persistent luminescence, the trap depth should be smaller than $1 \mathrm{eV}$ to enable charging and discharging at room temperature 2 .

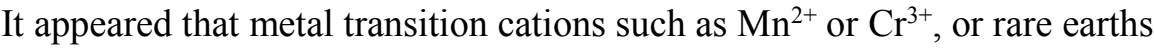
elements are good dopants for in-vivo optical bio-imaging based on persistent luminescence in the deep red/NIR range ${ }^{3}$ but others compounds listed below have recently demonstrated a lot of interest. Please notice that $\mathrm{ZnGa}_{2} \mathrm{O}_{4}: \mathrm{Cr}^{3+}$ (ZGO) is one of the most interesting long lasting phosphor in the gallate family. It shows deep red emission at $696 \mathrm{~nm}$ originating from the ${ }^{2} \mathrm{E}$ to ${ }^{4} \mathrm{~A}_{2}$ transition of $\mathrm{Cr}^{3+}$ ions ${ }^{13}$. A focus on this compound and its mains characteristics are presented in the following part of the chapter.

Table 1: Main materials used with metal transition (MT) cations and RE cations for red/ near infrared emission and applications in bioimaging.

\begin{tabular}{|c|c|c|c|}
\hline Hosts & Dopants & $\begin{array}{l}\text { Comments and applications } \\
\text { in bioimaging }\end{array}$ & Year and Refs \\
\hline $\mathrm{Gd}_{2} \mathrm{O}_{2} \mathrm{~S}$ & $\mathrm{Eu}^{3+}, \mathrm{Mg}^{2+}, \mathrm{Ti}^{4+}$ & $\begin{array}{l}\text { NPs regular shape, bimodality op- } \\
\text { tical / MRI }\end{array}$ & $14(2015)$ \\
\hline $\mathrm{Ca}_{3}\left(\mathrm{PO}_{4}\right)_{2} / \mathrm{HAP}$ & $\mathrm{Mn}^{2+}, \mathrm{Tb}^{3+}, \mathrm{Dy}^{3+}$ & $\begin{array}{l}\text { Fully Biocompatible, NPs and in- } \\
\text { vivo imaging }\end{array}$ & 15 (2015) \\
\hline $\mathrm{Ca}_{2} \mathrm{Si}_{5} \mathrm{~N}_{8}$ & $\mathrm{Eu}^{2+}, \mathrm{Tm}^{3+}$ & Bioimaging applications & $3 f(2012)$ \\
\hline $\mathrm{SrAl}_{2} \mathrm{O}_{4}$ & $\mathrm{Eu}^{2+}, \mathrm{Dy}^{3+}$ & $\begin{array}{l}\text { NPs, Functionalization; Bioimag- } \\
\text { ing applications, green emission }\end{array}$ & ${ }^{16}(2014,2018)$ \\
\hline $\mathrm{Ca}_{0.2} \mathrm{Zn}_{0.9} \mathrm{Mg}_{0.9} \mathrm{Si}_{2} \mathrm{O}_{6}$ & $\mathrm{Mn}^{2+}, \mathrm{Eu}^{2+}, \mathrm{Dy}^{3+}$ & $\begin{array}{l}\text { NPs, Functionalization, pioneer } \\
\text { work for Bioimaging: Cancer cells }\end{array}$ & $\begin{array}{l}{ }^{17}(2007,2011, \\
2012)\end{array}$ \\
\hline $\mathrm{Ca}_{1.86} \mathrm{Mg}_{0.14} \mathrm{ZnSi}_{2} \mathrm{O}_{7}$ & $\mathrm{Eu}^{2+}, \mathrm{Dy}^{3+}$ & $\begin{array}{l}\text { imaging, cell targeting } \\
\text { FRET and various bio-sensing ap- } \\
\text { plications }\end{array}$ & $18(2018)$ \\
\hline $\mathrm{CaMgSi}_{2} \mathrm{O}_{6}$ & $\mathrm{Mn}^{2+}, \mathrm{Eu}^{2+}, \mathrm{Pr}^{3+}$ & $\begin{array}{l}\text { NPs, Functionalization, Bioimag- } \\
\text { ing }\end{array}$ & ${ }^{19}(2011)$ \\
\hline
\end{tabular}


$\mathrm{MAlO}_{3}(\mathrm{M}=\mathrm{La}, \mathrm{Gd})$
$\mathrm{GdAlO}_{3}$

$\mathrm{ZnGa}_{2} \mathrm{O}_{4}$ in hollow cavity $\mathrm{ZnGa}_{2} \mathrm{O}_{4}$

\section{$\mathrm{ZnGa}_{2} \mathrm{O}_{4} / \mathrm{SiO}_{2}$ \\ $\mathrm{ZnGa}_{2} \mathrm{O}_{4} / \mathrm{Fe} 2 \mathrm{O} 3$ \\ ZGOCS@MSNs@ $\mathrm{Gd}_{2} \mathrm{O}_{3}$}

$\mathrm{Zn}_{1.1} \mathrm{Ga}_{1.8} \mathrm{Ge}_{0.1} \mathrm{O}_{4} / \mathrm{SiO}_{2}$
$\mathrm{Zn}_{3} \mathrm{Ga}_{2} \mathrm{Ge}_{2} \mathrm{O}_{10}$
$\mathrm{Zn}_{1.1} \mathrm{Ga}_{1.8} \mathrm{Ge}_{0.1} \mathrm{O}_{4} @ \mathrm{SiO}_{2}$
$\mathrm{Zn}_{1.25} \mathrm{Ga}_{1.5} \mathrm{Ge}_{0.25} \mathrm{O}_{4}$
$\mathrm{Zn}_{1.1} \mathrm{Ga}_{1.8} \mathrm{Ge}_{0.1} \mathrm{O}_{4}$
$\mathrm{Zn}_{3} \mathrm{Ga}_{2} \mathrm{Sn}_{1} \mathrm{O}_{10}$
$\mathrm{Zn}_{2.94} \mathrm{Ga}_{1.96} \mathrm{Ge}_{2} \mathrm{O}_{10}$
$\mathrm{Zn}_{3} \mathrm{Ga}_{2} \mathrm{Ge}_{2} \mathrm{O}_{10}$
$\mathrm{Zn}_{3} \mathrm{Ga}_{2} \mathrm{GeO}_{8}$
$\mathrm{LiGa}_{5} \mathrm{O}_{8}$

$\mathrm{Ca}_{3} \mathrm{Ga}_{2} \mathrm{Ge}_{3} \mathrm{O}_{12}$

$\mathrm{mSiO}_{2} @ \mathrm{Gd}_{3} \mathrm{Ga}_{5} \mathrm{O}_{12}$

$\mathrm{Sr}_{2} \mathrm{SnO}_{4}$

$\mathrm{SiO}_{2} / \mathrm{CaMgSi}_{2} \mathrm{O}_{6}$

YAGG (garnet)

$\mathrm{NaYF}_{4}+\mathrm{SrAl}_{2} \mathrm{O}_{4}$

$\mathrm{Sr}_{2} \mathrm{MgSi}_{2} \mathrm{O}_{7}$

$$
\begin{aligned}
& \mathrm{Mn}^{4+} / \mathrm{Ge}^{4+} \\
& \mathrm{Mn}^{4+}, \mathrm{Ge}^{4+} @ \mathrm{Au} \\
& \mathrm{Sm}^{3+}, \mathrm{Cr}^{3+}
\end{aligned}
$$$$
\mathrm{Cr}^{3+}
$$

$\mathrm{Cr}^{3+}$

$\mathrm{Cr}^{3+}, \mathrm{Gd}^{3+}$

$\mathrm{Cr}^{3+}$

$\mathrm{Cr}^{3+}$

$\mathrm{Cr}^{3+}$

$\mathrm{Cr}^{3+}, \mathrm{Eu}^{3+}$

$\mathrm{Cr}^{3+}$

$\mathrm{Cr}^{3+}$

$\mathrm{Cr}^{3+}, \mathrm{Yb}^{3+}, \mathrm{Er}^{3+}$

$\mathrm{Cr}^{3+}$

$\mathrm{Cr}^{3+}$

$\mathrm{Cr}^{3+}, \mathrm{Pr}^{3+}$

$\mathrm{Cr}^{3+}$

$\mathrm{Cr}^{3+}, \mathrm{Yb}^{3+}, \mathrm{Er}^{3+}$

$\mathrm{Cr}^{3+}$

$\mathrm{Cr}^{3+}, \mathrm{Yb}^{3+}, \mathrm{Tm}^{3+}$

$\mathrm{Pr}^{3+}, \mathrm{Yb}^{3+}$

$\mathrm{Cr}^{3+}, \mathrm{Nd}^{3+}$

$\mathrm{Nd}^{3+}$

$\mathrm{Eu}^{2+}, \mathrm{Pr}^{3+}, \mathrm{Mn}^{2+}$

$\mathrm{Er}^{3+}, \mathrm{Cr}^{3+}$
Bioimaging in pork tissue

${ }^{11}$ (2014)

${ }^{20}(2016)$

${ }^{21}$ (2018)

3e $(2014)^{22}$

(2014)

NPs, Functionalization, Bioimaging (cancer cells imaging, cell targeting, cytotoxicity, visible light stimulation NIR Photostimulation,

$\mathrm{X}$-rays activation

Oral administration \& breast cancer imaging

Toxicology analysis

Protobiotic analysis

Photodynamic therapies

NPs, Functionalization, Bimodality Optical/NMR imaging

NPs, core-shell structure, drug delivery

Cell labelling and magnetic vectorization

Multimodal nanoprobes

NPs, core-shell structure, drug delivery

Imaging of pork tissue, Photostimulation, cytotoxicity

bioimaging and drug delivery

Metastasis Tracking and Chemo-

photodynamic Therapy

Nanothermometry

Imaging of goldfish

NPs, Functionalization

Recognition of Breast Cancer

Cells

Upconversion

NPs, Functionalization, Bioimaging, Visible light stimulation, photostimulation

NIR Stimulation, Upconversion

In-vivo imaging

multimodal imaging and cancer therapy

Finger image

23 (2017),(2018)

24 (2018)

25 (2017)

26 (2017)

27 (2018)

28 (2015)

${ }^{29}(2014)$

${ }^{30}$ (2018)

31 (2017)

32 (2015)

${ }^{33}$ (2014)

34 (2018)

35 (2018)

36 (2017)

${ }^{37}(2014)$

38 (2013)

${ }^{39}$ (2015)

40 (2014)

${ }^{41}(2013,2014)$

42 (2014)

43 (2017)

${ }^{44}$ (2018)

45 (2014)

46 (2014)

${ }^{47}$ (2018)

tion

Photostimulation imaging of pork

tissue

Imaging in the second biological window

$\mathrm{Yb}^{3+}, \quad \mathrm{Tm}^{3+}, \quad$ Upconversion \& photodynamic $\mathrm{Eu}^{2+}, \mathrm{Dy}^{3+}$ therapy

$\mathrm{Eu}^{2+, 3+}, \mathrm{Dy}^{3+} \quad$ Photodynamic activation
${ }^{48}(2018)$

${ }^{49}$ (2016) 
Visualization of abdominal in-

Persistent luminescence phenomenon, whereby luminescent materials keep emitting light after the excitation has stopped, has intrigued people since several centuries. As this property occurs in inorganic materials when the excitation has been stopped, this is sometimes compared to the bioluminescence mechanism observed in some animals (such as fireflies and jellyfishes). Others fluorescent probes in the NIR range as reported in this book are the semiconductor quantum dots (QDs) or upconversion nanoparticles (UCNPs).

\section{Main characteristics of the persistent luminescence materials}

Long persistent luminescence is controlled by the slow liberation of trapped charge carriers at room temperature by a simple thermal de-excitation process. The luminescence can last for several minutes to hours after removal of the excitation source (typically several minutes of ultraviolet light) ${ }^{1,55}$. In persistent luminescence materials, energy can be stored by traps/defects that are charged under irradiation. Emergency signage that can be used in case of electricity failure is one of the main applications of these persistent phosphors, but others applications were proposed such as watch dials, when radioactive elements were fully forbidden more than twenty years ago, decorative objects and toys and more recently for bio-imaging as described in this review paper.

Fig. 1. left: Schematic of the energy levels and traps involved in the persistent luminescence mechanisms. Right: Partial transparency of living tissues in deep red range (see light through girl left hand and figure $11(c)$ ), extracted from Saint Joseph charpentier, G. de La Tour, 1643, Musée du Louvres, Paris, France

For the materials concerned with the persistent luminescence properties, there is in the literature plenty of compounds tested with various successes. Rare earth and metal transition cations have been widely used as dopant for 
persistent luminescence materials and in last years. More than two hundreds combinations of host materials and activator ions have been depicted. The reader could see recent reviews and book chapter on the topic ${ }^{2,56}$. For bioimaging and in-vivo application, as seen in figure 1, the past five years have witnessed several major advances to establish deep red/near-infrared emitting persistent luminescence nanomaterials (called in the paper PLNPs as acronym for Persistent Luminescence NanoParticles) as a novel, approach for real-time used in-vivo in small animal.

The main requirements that the materials must fulfil for this application are the following: (i) compounds prepared as nanoparticles (PLNPs with size $<$ $100 \mathrm{~nm}$ ) and even ultrasmall nanoparticles ( $<10 \mathrm{~nm}$ ) (ii) intensive emission extending in the deep red toward the near infrared range in the first or second windows corresponding to the tissue transparency ${ }^{57}$, (iii) efficient functionalization, (iv) stability in aqueous solution (v) persistent emission over hours. These points are the reasons why applications using deep red emitting persistent phosphors for bio-applications were barely investigated at the first step of the development of the persistent phosphors in 1996 and the investigation started in 2007 after our pioneer paper ${ }^{17 a}$. Several materials were further developed for imaging applications (see figure 1 and review papers ${ }^{56}$ ). Notice that at first all the researches were focused in the deep-red range (high transmission range of the living tissue, see also figure 1) where the Si detector also reaches its maximal sensitivity. More recently researchers extend the range to the second and third biological windows (BW) even if the results are still very preliminary in that $1000 \mathrm{~nm}-1350 \mathrm{~nm}$ spectral range (BW-2) and above $1500 \mathrm{~nm}(\mathrm{BW}-3)$ as presented in the following part of the chapter. In the development of the new phosphors with long persistent luminescence for bio-applications, one should keep in mind that various synthesis strategies are used for small size preparation of PLNPs with good crystallinity but also with the optimum of defects at the origin of the persistent luminescence. Hydrothermal, solvothermal, sol-gel, co-precipitation and microwaves methods have been widely used. In addition, effective surface functionalization strategies along with the bio-compatibility issues required attention to make them useful for in-vivo bioimaging.

\section{Persistent luminescence mechanisms}

The physics behind the phenomenon is however not that simple and intensive research has been carried out the last years. For the trapping processes, which is the primary very important step, two kind of traps are envisioned:

(i) Intrinsic defects and optimization of the traps by composition variation and thermal annealing. Intrinsic defects have been well identified in lot of materials. ${ }^{10 a}, 58$ In garnet hosts, antisite defects for instance are very likely, 
they shorten some $\mathrm{Y}-\mathrm{O}$ bonds and create shallow electron traps close to the conduction band. Antisite defects in the vicinity of $\mathrm{Cr}^{3+}$ ions have been proposed to be involved in the persistent luminescence mechanism of the zincgallate spinel host ${ }^{13,59}$. One should also notice that thermal annealing under reducing atmosphere is often used to create or enhance intrinsic traps such as oxygen vacancies, which correspond to electron traps and can be responsible for the persistent luminescence ${ }^{60}$.

(ii) Optimization of the traps by co-doping. Co-doping is the second strategy that has been intensively tested to enhance the persistent luminescence. Codoping with one or two lanthanides cations are most of the time used to enhance the property. For instance, $\mathrm{Dy}^{3+}$ was used as electrons trap in the first hybrid enstatite/diopside silicate for the proof of concept of the in-vivo bioimaging application with PLNPs ${ }^{17 a}$. Moreover it appeared that $\operatorname{Pr}^{3+}$ was indeed better when only the diopside bandgap was considered ${ }^{11}$. The variation of traps depths strongly depends on the couple host/dopant and corresponds to a so-call bandgap engineering as introduced in previous works ${ }^{61}$, with the prediction of the energy level diagram ${ }^{62}$. Such bandgap engineering was proposed in various hosts used for persistent luminescence but was also tested with success in others Photonic applications such as scintillation and lighting. It is then currently possible to vary the position of the conduction band and the traps depth by varying the composition playing with cationic and anionic substitutions or a careful choice of the doping cation for an optimal couple composition/dopant.

To go in deeper understanding, knowledge of the energy formation of defects, defects stability and defects energy position are required, through band structure and defects calculations ${ }^{63}$. The persistent luminescence mechanism has been characterized by lots of different spectroscopies including optical, EPR to control the origin of defects, ${ }^{64} \mathrm{X}$-rays spectroscopies ${ }^{65}$ to give insights to the mechanism, thermoluminescence ${ }^{19}$ and photoconductivity ${ }^{66}$ to measure the traps depth ${ }^{10 a, 67}$. In the case of electron traps and hole traps ${ }^{68}$, the stored charges can be released by various processes as expressed in the following part such as thermal ${ }^{69}$, optical ${ }^{70}$ or other physical stimulations ${ }^{71}$, resulting in stimulated emissions from the active recombination centers.

\section{$\mathrm{ZnGa}_{2} \mathrm{O}_{4}: \mathrm{Cr}$ nanoparticules for persistent luminescence applications}

If metal transition doped $\mathrm{ZnGa}_{2} \mathrm{O}_{4}$ nanoparticles can be obtained by different techniques, our activity recently focus on the hydrothermal synthesis assisted by microwave heating in order to obtain ultrasmall nanoparticles with persistent luminescence properties. To avoid sintering and keep the nanometric size during the following thermal treatment, the nanoparticles are 
embedded in a silica layer using a sol-gel chemistry way. A mixture of TEOS:EtOH 1:4 is added to a basic solution of nanoparticles. Doped with trivalent chromium for deep red /NIR emission, the obtained $\mathrm{ZnGa}_{2} \mathrm{O}_{4}: \mathrm{Cr}^{3+}, \mathrm{Bi}^{3+} @ \mathrm{SiO}_{2}$ nanoparticles are then calcined in air during $2 \mathrm{~h}$ at $1000{ }^{\circ} \mathrm{C}$. The nanoparticles are monodisperse with a sub- $10 \mathrm{~nm}$ size ${ }^{72}$, To better characterize the persistent luminescence properties of the $\mathrm{ZnGa}_{2} \mathrm{O}_{4}: \mathrm{Cr}^{3+}$ nanocrystals, we also recently proposed with colleagues from Orleans, France ${ }^{73}$ to prepare these nanocrystals embedded in a glass phase in the so-called ZGO nano glass-ceramics. The TEM picture of both nanoobjects are presented in figure 2 . The nanoparticles embedded in glassy matrix present an average diameter about $16 \mathrm{~nm}$ while after hydrothermal synthesis assisted by microwave, diameter nanoparticles smaller than $10 \mathrm{~nm}$ can be obtained (see figure 2). The nanoparticles are spherical and well dispersed. In both cases after crystallization at $900{ }^{\circ} \mathrm{C}$ and thermal treatment at $1000{ }^{\circ} \mathrm{C}$ respectively, the obtained nano-objects are well crystallized in the pure spinel phase and present persistent luminescence properties.

Fig 2. TEM pictures of a) $\mathrm{ZnGa}_{2} \mathrm{O}_{4}: \mathrm{Cr}^{3+}$ (ZGO) nanoparticles embedded in glass matrix $\left(T C=900{ }^{\circ} \mathrm{C}\right)$ b) ZGO nanoparticles after hydrothermal synthesis assisted by microwave heating, associated distribution diagram, adapted from ${ }^{74,73}$.

$\mathrm{Cr}^{3+}$-doped ZGO nanoparticles photoluminescence and persistent luminescence spectra are presented figure 3 . Several contributions of the chromium emission are well identified: the $\mathrm{R}$ line corresponding to the zero phonon line. Stokes and anti-Stokes phonon side bands (S-PSB and AS-PSB respectively) were also recognizable. The $\mathrm{N} 2$ line is attributed to the emission of a $\mathrm{Cr}^{3+}$ ion in the vicinity to an antisite defect ${ }^{13}$. The persistent luminescent emission spectra is mostly dominated by the $\mathrm{N} 2$ line, indicating that these cations, spatially closed to the electron traps are partly responsible of persistent luminescence (see following part). Figure 3 shows the persistent luminescence decay after 2 min of UV irradiation of ZGO: $\mathrm{Cr}^{3+}$ nanoparticles embedded in glass. With these ultrasmall nanoparticles, it is possible to detect the signal more than 2 hours after swithing off the UV lamp.

Fig. 3: Left, (top) Emission spectra of photoluminescence and (bottom) persistent luminescence at room temperature, adapted from ${ }^{13}$. Right: Persistent luminescence decay of $\mathrm{ZnGa}_{2} \mathrm{O}_{4}: \mathrm{Cr}^{3+}$ nanoparticules (within more than 2 hours) adapted from $^{73}$.

As experimentally determined as well as calculated ${ }^{75,75 b}$, in such nanomaterials, antisites defects around the $\mathrm{Cr}^{3+}$ cations are needed to get persistent luminescence properties. NMR and EPR magnetic spectroscopies can 
gives some insights on the disorder, and on the surrounding of the dopant $\left(\mathrm{Cr}^{3+}\right)$ or the host $\left(\mathrm{Ga}^{3+}\right)$ while thermoluminescence give insights on the persistent luminescence capability ${ }^{73}$. In the particular case of $\mathrm{ZnGa}_{2} \mathrm{O}_{4}: \mathrm{Cr}^{3+}$ and derivatives, electron paramagnetic resonance (EPR) is a technique of choice to learn about $\mathrm{Cr}^{3+}$ environments. Indeed, there is a splitting of the ${ }^{4} \mathrm{~A}_{2}$ chromium level into two degenerated states (one $\mathrm{m}_{\mathrm{s}}= \pm 3 / 2$ and one $\mathrm{m}_{\mathrm{s}}$ $= \pm 1 / 2)$ due to the crystal field distortion and the spin orbit coupling. An application of a magnetic field can raise the degeneracy of these levels. Depending on the $\mathrm{Cr}^{3+}$ vicinity, the splitting of these levels may be different leading to various EPR signals. Several EPR studies have been performed on $\mathrm{ZnGa}_{2} \mathrm{O}_{4}: \mathrm{Cr}^{3+}$, resulting in a better understanding of the local material structure and the possibility to distinguish several $\mathrm{Cr}^{3+}$ environments using simulations. First, the simulations on powder phosphors have shown that five different $\mathrm{Cr}^{3+}$ surroundings may exist in $\mathrm{ZnGa}_{2} \mathrm{O}_{4}: \mathrm{Cr}^{3+}$ material ${ }^{75 a}$. The results also strengthened the assumption about the role of antisite defects on persistent luminescence properties. Indeed, it has been demonstrated that the charge trapping in $\mathrm{ZnGa}_{2} \mathrm{O}_{4}: \mathrm{Cr}^{3+}$ may be related to two antisite defects in the $\mathrm{Cr}^{3+}$ neighborhood $(\mathrm{Cr}-\gamma, \mathrm{Cr}-\delta, \mathrm{Cr}-\varepsilon)$. We recently demonstrated that simulations using these five $\mathrm{Cr}^{3+}$ also perfectly fits our nano-crystals embedded in glass matrix ${ }^{73}$ (see figure 4). An important EPR result in this system is the possible quantification of chromium environment. This quantification enables the dependence on synthesis parameters. Indeed, we can notice a global increase of undistorted $\mathrm{Cr}^{3+}$ environment when $\mathrm{T}_{\text {cryst }}$ increases revealing a better symmetry around $\mathrm{Cr}^{3+}$ in agreement with the improvement of crystalline quality. However, the persistent luminescence properties of lower crystallization temperature materials are poor, this may be due to the presence of parasitic defects due to poor crystallinity leading to quenching processes at the expense of the radiative processes.

Thermoluminescence (TL) or thermally stimulated luminescence (TSL) is the most commonly used technique to demystify the trap number and their depths. This is a required characterization technique prior to persistent luminescence compounds developemnt. At first, in the thermoluminescence experiments, traps of the the compounds mustbe filled by optical (from Xrays to NIR photons) or others stimulations. Notice that mechanoluminescence ${ }^{76}$ is also recently an important field of investigation. As mentioned above, in a second step thermal energy or others excitation processes, can release these traps. During the TL experiments, the sample is linearly heated, from $10 \mathrm{~K}$ to $600 \mathrm{~K}$ in our facility. When the thermal energy brought by the heater is sufficient $i . e$. in the order of the energy difference between a recombination center and the trap, charges start to be de-trapped. After being released, charges can either be trapped again in the same or others traps in 
the vicinity or recombine on the emitted centre. In this latest process, thermoluminescence occurs and can be recorded. The result of the experiment, as presented in figure 4, shows luminescent intensity as a function of the temperature. The number and position of the glow curve peaks give insights on the traps depths and distributions. Notice that the trap depth can also be estimated from the thermoluminescence profile. Regarding to the glow curve shape, several equations can link the trap depth to the peak temperature ${ }^{77,78}$. In case of broader bands, which appears to be often the case for PLNPs, a simple estimation can be made using ${ }^{79}$ :

$$
E=\frac{T_{m}}{500}
$$

Where $E$ is the trap depth and $T_{m}$ is the temperature of the peak maximum. For the persistent luminescence properties at room temperature, the release should occur at room temperature, in case of in-vivo applications it has to be close to the living tissues temperature. This means that materials should present thermoluminescence peaks centred at $c a .310 \mathrm{~K}$ to be suitable for this application. Another option is to design materials with several trap depths. One kind of traps corresponding to room temperature and deeper traps, that cannot be thermally emptied at room temperature. In this case, a possible invivo re-activation of the persistent luminescence via trap redistribution using optical stimulation (using NIR light) can be envisionned.

The thermoluminescence results for $\mathrm{ZnGa}_{2} \mathrm{O}_{4}: \mathrm{Cr}^{3+}$ are displayed on figure 4 for several particles size and various shapes. The bulk material shows a relatively sharp thermoluminescence peak, labelled as the main peak, centred at $318 \mathrm{~K}$, making it suitable for in-vivo imaging based on persistent luminescence. It also shows two shallow traps, weaker in intensity around $145 \mathrm{~K}$ and $200 \mathrm{~K}$. Going from bulk material elaborated via solid state method to nanoparticles elaborated by hydrothermal synthesis assisted by microwave heating, the thermoluminescence glow curve becomes quite different. Indeed, the corresponding profile presents a broad signal that seems to be composed of two major contributions, one around $210 \mathrm{~K}$

Fig. 4: Left : Thermoluminescence glow curves with different sizes and shapes and right: Simulation and experimental EPR spectra for the ZGO:Cr, adapted from ${ }^{73}$.

Table 2 : EPR parameters and $\mathrm{Cr}^{3+}$ surrounding adapted from ${ }^{73}$

\begin{tabular}{l|cccc} 
& $\mathrm{Cr}_{\alpha}$ & $\mathrm{Cr}_{\beta}$ & $\mathrm{Cr}_{\gamma}+\mathrm{Cr}_{\delta}+\mathrm{Cr}_{\varepsilon}$ & $\Phi$ \\
\hline ZGO-GC $900{ }^{\circ} \mathrm{C}$ & $5.4 \%$ & $59.9 \%$ & $24.5 \%$ & $10.2 \%$ \\
ZGO-GC $1000{ }^{\circ} \mathrm{C}$ & $18.2 \%$ & $52.4 \%$ & $21.5 \%$ & $7.9 \%$
\end{tabular}




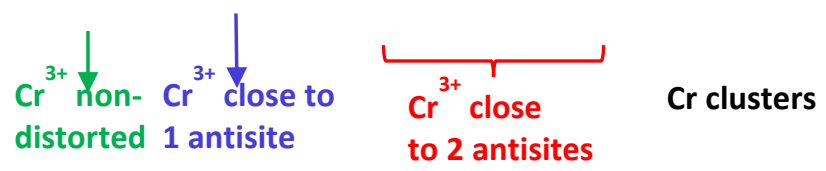

and one around $300 \mathrm{~K}$. The first one can be related to the shallow traps whereas the second can be related to the previous main peak. As the surface over volume ratio increases when the size is reduced, surface defects may have a major contribution in nanoparticles. With that in mind it has been assumed that the shallow traps can be related to surface defects. The thermoluminescence glow curve of $\mathrm{ZnGa}_{2} \mathrm{O}_{4}: \mathrm{Cr}^{3+}$ glass ceramics elaborated at $900{ }^{\circ} \mathrm{C}$, presented on the same figure (see Fig. 4), presents a broad main peak centred at $c a .310 \mathrm{~K}$. The two shallow traps can be observed as humps enlarging the main peak at around $145 \mathrm{~K}$ and $205 \mathrm{~K}$. In the glass ceramics samples, the surface over volume ratio is very high because of the nanoscale of the crystals. Still, the surface defects quantity may be very low comparing to nanoparticles elaborated via microwave assisted hydrothermal method as the nanocrystals are here embedded in a glassy matrix. This can explain the relatively low response of shallow traps, as it is assumed that they are related to surface defects. However, the main response peak appears broader in glass ceramics samples compared to bulk material. This has previously been explained by the crystal quality of the material.

\section{Biocompatibility}

To be used in-vivo, the nanoprobes should have the lowest toxicity. The main matrices presented above are either NPs incorporated into silica (it can also be mesoporous silica as seen below) or oxide-based NPs. Since they are designed for the sustained release of drugs, the tissue compatibility required a careful investigation. This was done by several groups (see for instance $\left.{ }^{80}\right)$. No pathological abnormality could be observed in both gross and microscopic histological examinations of various tissues including heart, liver, spleen, lung and kidney up to one month after vein injection into mice, suggesting that the mesoporous silica PLNPs had not caused significant tissue toxicity and inflammation even they had not completely be degraded. 
It was confirmed that neither gross nor histopathological abnormalities could be observed in the major organs of mice, such as in liver, spleen, kidneys, heart, intestines, stomach, muscles or lungs ${ }^{81}$. Furthermore, at a high vein-injection dose of $50 \mathrm{mg} \cdot \mathrm{kg}^{-1}$ per day, the acute toxicity of PLNPs was almost negligible compared with the blank control according to the monitoring of the body-weight change, the visible and/or palpable dermal infection, the presence of ascites, the grooming or the impaired mobility. At an extremely high dose of $1200 \mathrm{mg} \cdot \mathrm{kg}^{-1}$, no mouse survived after intraperitoneal or intravenous injection of MCM-41-type or SBA-15-type mesoporous silica nanoparticles (MSNs), however the subcutaneous injection did not cause death at an equally high administration dose and doses of up to 200 mg.kg- ${ }^{-1}$, which was high enough for drug loading and delivery owing to their high drug loading capacities, was always safe by both intraperitoneal and intravenous injection ${ }^{82}$.

Concerning persistent luminescence nanoparticles by themselves, two articles have been recently published concerning biocompatibility and toxicity assays in-vivo. The first one was reported in 2017 by Ramirez-Garcia et al. In this study, mice were injected with a single intravenous administration of either hydroxylated or PEGylated persistent luminescence nanoparticles at different concentrations, from 1 to $8 \mathrm{mg}$ per mice and a set of standard tests were carried out 1 day, 1 month and even 6 months after the administration ${ }^{25}$. High concentrations of hydroxylated nanoparticles generate structural alterations at histology level, endoplasmic reticulum damage and oxidative stress in liver, as well as rising in white blood cells counts. A mechanism involving the endoplasmic reticulum damage could be responsible of the observed injuries in case of ZGO-OH. On the contrary, no toxicological effects related to PEGylated nanoprobes treatment were noted during the invivo experiments, denoting the protective effect of PEG-functionalization and thereby, their potential as biocompatible in-vivo diagnostic probes. In 2018, Zhang and co-workers reported a 60 days in-vivo study of ZGO derivatives $\left(\mathrm{Zn}_{1.1} \mathrm{Ga}_{1.8} \mathrm{Sn}_{0.1} \mathrm{O}_{4}: \mathrm{Cr}^{3+}\right)$ compound. In this work, healthy $\mathrm{Balb} / \mathrm{c}$ mice were intravenously injected with ZGO derivative at a dose of 10 $\mathrm{mg} / \mathrm{kg}$. ZGO pre-irradiated with a $254 \mathrm{~nm}$ UV lamp was also set as one of the factors to evaluate the possible effect of NIR persistent luminescence of ZGO in-vivo. No signs of apparent weakness, spontaneous animal death and significant body weight gain or loss were observed within 60 days. It was found that all of the parameters were in the normal reference range. In the haematological analysis, various serum biochemical parameters were measured with particular attention paid to liver and kidney function. Indicators of kidney function, including creatinine and urea nitrogen, were also within normal ranges and were similar to these of control mice. These results show 
no obvious injury to the liver and kidney with ZGO exposure in mice, even at long exposure times. Based on long-term in-vivo biodistribution studies, the major organs from mice were sliced for hematoxylin and eosin staining and histological examination to determine whether or not ZGO exposure caused tissue damage, inflammation or lesions. The structures of the organs exhibited hardly any difference from the control group. No apparent histopathological abnormalities or lesions were found in any of the experimental groups. All of these data suggested that no significant toxicity was induced by ZGO injection, even up to 60 days.

\section{Excitation capabilities and long term in-vivo imaging.}

Though intended for diagnosis applications in living animals, persistent luminescence nanoparticles suffer from severe limitations. First, as the release of photons is thermally activated, accumulations of the signal (from seconds to minutes) are required during recording and materials with intensive persistent luminescence on one side and low noise detector on the other side should be used. The second point concerns the excitation mechanisms of the PLNPs but recent improvements have been made as described in this part of this chapter. Indeed the first generation of PLNPs has to be excited ex-vivo by UV light prior to systemic administration preventing long-term imaging in living animal. Depending on the nanoparticle characteristics, slow accumulation of stealth nano-carriers within malignant stroma by the enhanced permeability and retention effect usually requires from 2 to 24 hours ${ }^{83}$. This was far too long in relation to the emission from persistent luminescence nanoparticles, which hardly exceeds one hour in-vivo.

To overcome this major restriction, developments of new materials and of new modalities have been undertaken. First, efforts to optimized compositions and enhanced optical characteristics have been made. In that sense, compounds based on gallate and gallo-germanate spinels compounds have attracted large attention, due to their bright deep persistent luminescence when doped with trivalent chromium $\left(\mathrm{Cr}^{3+}\right)$ after UV excitation in comparison with the previously used silicate nanoprobes. Then the second point was to excite the persistent luminescence material at lower energy in the biological window if possible, longer time after the injection. The new modality has been proposed in different ways as seen in Figure 5. 
Figure 5 summarizes the various approaches that can be followed for long term in-vivo imaging with persistent luminescent nanoparticles: A suspension of PLNPs in a biological buffer can be pre-activated ex situ, then injected into the animal and placed under a photon-counting system to detect the emitted persistent luminescence signal (see step 1, Fig. 5). PLNPs can be activated or re-activated in situ (after the injection) through animal tissues (step 2, Fig. 5). This breakthrough for in-vivo optical imaging allows the most simple and convenient recovery of the persistent luminescence signal, whenever required. The efficiency is lower than for the persistent luminescence under UV excitation (step 1) but is indeed sufficient to be detected and to localize the probe in-vivo. Furthermore for some inorganic persistent luminescent NPs, when deeper traps are observed in the thermoluminescence spectra such as in garnet and spinels hosts, deep-red persistent emission can be stimulated by near infrared light, as the traps can be depopulated by low-energy light stimulation in the so-called photostimulated persistent luminescence (PSPL) ${ }^{22,70,84}$. The photostimulation capability of several materials is widely reported ${ }^{85}$ and researchers have focused their attention on the $\mathrm{Cr}^{3+}$ doped samples. The photostimulation technique has been used over the years for UV dosimetry, as well as for dating geological and archaeological materials ${ }^{86}$. One can adjust the depth of the traps responsible for the persistent luminescence and therefore to control carefully the composition. In that case, the release of the traps and thus the emission could be started at the convenience of the user using a red/near infrared LED for instance which will be in the best transparency range. The first preliminary carried out tests have shown the originality and feasibility of this new modality ${ }^{87}$. The excitation energy for charge detrapping may vary from red to NIR lamps, LED or laser sources. The photostimulation or excitation by lowenergy light can also be carried out by additional step, corresponding to

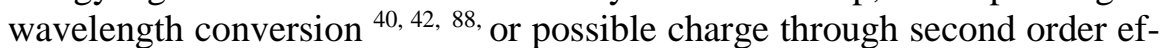
fects under high excitation power ${ }^{73,89}$.

Fig 5: Top: different strategies to perform in-vivo optical imaging with persistent luminescence nanoparticles (PLNP). (1) Excitation of a suspension of nanoparticles followed by tail vein injection and optical imaging using a photon counting camera. (2) Once the in-vivo persistent luminescence signal has completely disappeared, some PLNP can give further persistent luminescence signal either by photo-or X-rays stimulations possibly giving $n$ decay signals. (3) Some PLNP can be excited without preliminary excitation (with lower efficiency) in the animal body using visible, near infrared -for upconversion- or X-rays photons, Bottom Traps could be emptied by a near infrared source (energy 1eV) showing the crucial role of charge-storage to deep traps and photo- 
transfer to shallow traps leading to persistent luminescence. This demonstrated the photostimulation capability at convenience time. Within this experiment, one observed long-lasting phosphorescence under $977 \mathrm{~nm}$ light excitation ${ }^{87}$, making in-vivo excitation of the spinels probes envisioned and possible long term imaging applications.

However, in-vivo tracking is still hindered by its limited penetration in tissue even in the near infrared. An alternative way is to use NIR or X-ray as excitation source for imaging techniques. Indeed compared to the traditional excitation source, X-ray possesses competitive advantages of weaker scattering and deeper penetration depth in tissues, as well as simplified image reconstruction for optical tomography. Developing X-ray rechargeable persistent luminescence nanoplatform, by combining the advantages of X-ray excitation and NIR persistent emission in the second biological window, will enable to localize tumors and achieve treatment simultaneously ${ }^{90}$. This opens the door for achieving deeper tissue and higher sensitivity optical bioimaging with better spatial resolution. An example of such modality with ZGO:Cr PLNPS is presented in the following part of this chapter.

\section{Strategies developed to perform long time imaging}

The pioneer work using persistent luminescence nanoparticles (PLNPs) for optical in-vivo bioimaging was reported in 2007 by Scherman and co-workers ${ }^{17 a}$. As discussed in the previous section, to be used in-vivo, the probe should have a nanometric scale and should emit light in the transparency window (> $650 \mathrm{~nm}$ ). In their work, the authors prepared a silicate doped with $\mathrm{Eu}^{2+}, \mathrm{Dy}^{3+}$ and $\mathrm{Mn}^{2+}$ and in-vivo imaging without any background was performed for 30 min to 1 hour without any in-vivo excitation, allowing performing in-vivo imaging without autofluorescence. Then after these pioneer works, lots of bio-applications and various modalities have been presented as seen Table 1, and some of them are detailed in the following part of the chapter. To overcome this major restriction and to allow longer time imaging, in 2014 Maldiney et al. changed the matrix and used zinc gallium oxide doped with $\mathrm{Cr}^{3+3 e}$. As can be seen on Figure 6, contrary to the first silicate type generation, this material has several excitation peaks, among them one being at the limit of the tissue transparency window (Figure 6A) that can also sensitized the persistence luminescence. On nanosized $\mathrm{ZnGa}_{2} \mathrm{O}_{4}: \mathrm{Cr}$, they observed a persistent luminescence decay signal after both $U V$ and activation with visible orange/red light-emitting diodes (LEDs) (Figure 6B). A suspension of this material dispersed into 5\% glucose was injected into mice, and for the first time the authors have shown that the probe could be activated in-vivo with orange/red light-emitting diodes. The authors have also shown that UV pre-excitation before LED re-activation is favourable 
but not necessary (Figure 6C and 6H). In such conditions, there was no more time limit and the probe could be detected in-vivo whenever wanted through a simple excitation with the LEDs (Figure 6E-G).

Fig. 6. In-vivo imaging using in situ excitable PLNPs. (a-c) Optical properties of powder after either UV or visible excitation. (d-h) In-vivo excitation of un-functionalized PLNPs (e) or stealth ZGO in healthy $(f)$ on tumor bearing mice $(\mathrm{g})$, adapted from ${ }^{3 e}$.

It is of great importance to develop deep red/NIR PLNPs with rechargeable nature in-vivo by a deep tissue penetrating source (see figure 1, old painting showing only red light through living tissues). Recent years have witnessed the rapid development of utilizing innovative excitation sources for imaging techniques ${ }^{91}$. For instance X-ray photon energies are able to stimulate luminescent centers in phosphors and then generate light. Furthermore, compared with the traditional excitation sources (UV/visible/NIR), X-ray possesses competitive advantages of weaker scattering and deeper penetration depth in tissues and simplified image reconstruction for optical tomography ${ }^{92}$. As a proof of concept, Xue et al selected $\mathrm{ZnGa}_{2} \mathrm{O}_{4}: \mathrm{Cr}^{3+}$ PLNPs as models for X-ray-activated NIR persistent emission ${ }^{23 b}$. In-vivo NIR persistent luminescence bioimaging based on these X-PLNPs was demonstrated (see figure 7). More importantly, these X-PLNPs were also repeatedly charged by $\mathrm{X}$-rays at a deep location up to $20 \mathrm{~mm}$. These results revealed that X-ray could act as a new excitation source for persistent renewable bioimaging with a deep penetration depth based on NIR PLNPs.

Fig. 7. (a) Principle of in-vivo imaging using X-ray excitation. (b) Applications in-vivo, adapted from ${ }^{23 b}$ and ${ }^{93}$.

\section{Multimodal imaging}

Multimodal imaging has drawn much attention in biomedical applications because it provides more accurate, complete, and reliable information on diagnosis ${ }^{94}$. Each imaging modality has its own advantages and disadvantages regarding sensitivity, spatial/temporal resolution, and penetration depth. The NIR optical imaging possesses the advantage of high sensitivity 
but limited spatial resolution. In contrast, MRI provides excellent spatial resolution and unlimited depth penetration but remains at an inherently low sensitivity ${ }^{95}$. The combination of NIR emitting PLNPs and MRI contrast agent into one single nanoplatform would offer attractive synergistic advantages in biomedical imaging with high sensitivity, good spatial resolution, high signal over noise ratio, and no ionizing radiation.

Several strategies have been reported using gadolinium to have access to bimodal imaging PLNPs. In 2014, Yan and co-workers reported the surface functionalization of $\mathrm{Zn}_{1.1} \mathrm{Ga}_{1.8} \mathrm{Ge}_{0.1} \mathrm{O}_{4}$ with DTPA-Gd complexes to get bimodal imaging agents, able to be detected both by optical imaging and as a positive $\mathrm{T}_{1}$ MRI contrast agent ${ }^{96}$. In 2015, Maldiney et al. reported another method to prepare PLNPs-based bimodal imaging agent. In their strategy, instead of using the surface of the PLNPs to link DTPA-Gd complexes, the authors co-doped their NPs by incorporating various amount of $\mathrm{Gd}^{3+}$ ions at the beginning of the synthesis, by substituting $\mathrm{Ga}^{3+}$ ions ${ }^{28}$. In such conditions, a negative contrast was obtained, with a $\mathrm{r}_{2}$ value close to $60 \mathrm{mM}^{-1} . \mathrm{s}^{-}$ ${ }^{1}$. In 2017, Zou et al used a third strategy to prepare bimodal imaging agents. In their work, a novel core-shell structure multimodal imaging probe was prepared, based on the coverage of of mesoporous silica nanoparticles (MSNs) loaded $\mathrm{ZnGa}_{2} \mathrm{O}_{4}: \mathrm{Cr}^{3+}, \mathrm{Sn}^{4+}$ (ZGOCS@MSNs) by a $\mathrm{Gd}_{2} \mathrm{O}_{3}$ shell $(\sim 1.5 \mathrm{~nm})^{31}$. Compared with previously reported $\mathrm{Gd}^{3+}$-based NIR persistent luminescence-based multimodal nanoprobes, the as-prepared nanoparticles enable surface available, no persistent intensity loss and only a slight size increase.

Instead of gadolinium, ultrasmall iron oxide nanoparticles (also called USPIO) are used in clinic as negative $\left(\mathrm{T}_{2}\right)$ MRI contrast agents. In 2015, Teston et al reported the first synthesis of mesoporous nanohybrids (MPNHs) composed of a combination of PLNPs and USPIOs embedded into a mesoporous silica structure to get a bimodal imaging agent ${ }^{97}$. In addition of its bimodal imaging property, the authors showed that this nanoplatform could be attracted by a magnet. They used this property to label and attract cells in-vivo ${ }^{30}$.

\section{Theranostics nanoprobes}

During the past 10 years, it has been shown that diagnosis and therapy could be combined within a single multifunctional nanomaterial, known as theranostic nanoparticles ${ }^{98,3 \mathrm{~b}}$. The ideal theranostic nanomaterial should possess several advantages ${ }^{99}$ : (i) the ability for highly selective accumula- 
tion in the diseased tissue, (ii) the capability of delivering an effective therapeutic action selectively, and (iii) safety concerns and the material should undergo biodegradation into nontoxic byproducts. Such nanomaterials are one of the keys for detection and treatment of early stage cancer in the $21^{\text {st }}$ century ${ }^{100}$. Theranostic nanoparticles are still in the very early translational stages, with nearly all efforts devoted to preclinical studies and no clinical trials to date. In this section, we will highlight the recent use of PLNPs for the development of new theranostic nanoprobes.

Typically, mesoporous silica $\left(m \mathrm{SiO}_{2}\right)$ can be used as a promising drug carrier because of its stable mesoporous structure, high specific surface area and good biocompatibility ${ }^{101}$. Using mesoporous silica alone as a drug carrier it appears impossible to effectively locate a target site (i.e., tumor) and monitor in real time due to the lack of detectable signals. In 2014, Maldiney et al introduced a multifunctional nanoplatform based on persistent luminescence nanoparticles for both in-vivo optical imaging and drug delivery ${ }^{29}$. Taking advantage of the well-known biocompatibility of mesoporous silica and non-toxic ZGO, the authors modelled a novel core-shell structure on the basis of a hybrid chromium-doped zinc gallate/mesoporous silica architecture specifically designed to allow both highly sensitive optical detection through living tissues and concomitant drug delivery. Employing doxorubicin as a drug model, the authors demonstrated that these mesoporous persistent luminescence nanophosphors can be successfully loaded with an anticancer agent, and subsequently initiate its progressive release in a $\mathrm{pH}$ sensitive manner. The use of such doxorubicin-loaded theranostic agent is finally shown to induce acute cytotoxicity toward U87MG cells in vitro, preserved persistent luminescence properties, and allowed both sensitive and non-invasive localization of the carrier in-vivo.

In 2016, Zhang and co-workers developed another core-shell NPs composed of $\mathrm{Gd}_{2} \mathrm{O}_{2}, \mathrm{ZGO}$ and $\mathrm{mSiO}_{2}{ }^{102}$. This multimodal nanoprobe could be detected both by MRI and optical imaging and was used to monitor it's biodistribution in healthy and tumor bearing mice after loading with doxorubicin (see Figure 8).

Fig. 8. Synthesis procedure of mesoporous ZGO, loading with Dox and in-vivo application, adapted from ${ }^{102}$.

\section{Photodynamic therapy with PLNPs}


A few photosensitizers (PSs), such as Porfimer sodium, have been approved by the United States Food and Drug Administration (FDA) to treat certain cancers. However, most of the available PSs for PDT can only be activated under the UV/visible light $(<700 \mathrm{~nm})$ with low tissue penetration. New strategies in order to use such molecules in better conditions are under investigations.

Photodynamic therapy (PDT) is a relatively new modality for cancer treatment ${ }^{103}$. PDT consists of three essential components: light, oxygen, and a photosensitizer ${ }^{104}$. Photosensitizers, often pharmacologically inactive without illumination, can be activated by light of a specific wavelength. This activation is followed by transfer of energy to nearby oxygen molecules to generate cytotoxic reactive oxygen species (ROS), most importantly singlet oxygen $\left({ }^{1} \mathrm{O}_{2}\right)$. PDT is a relatively less invasive treatment modality, inducing low systematic toxicity and causing little intrinsic or acquired resistance. One primary downside of PDT, however, is its inability to treat tumors located deep under the skin due to the short penetration depth of light in tissues ${ }^{105}$. This problem can be partially alleviated by advanced light-delivering technologies that allow for illumination of certain internal cavities, such as the bladder, prostate, lung, and oesophagus. Nevertheless, it is considered as challenging or impossible for conventional PDT to treat tumors of large volumes or multiple loci. High X-rays dose (>5.0 Gy) are needed for efficient cancer therapy, and this dose was comparable or even higher than the fraction dose used in clinical radiotherapy ${ }^{106}$. Many researches have shown that high-dose X-ray irradiation inevitably causes damage to normal tissues 107.

In this regard, reducing X-ray dose is a major concern for deep-tissue PDT practical applications. Persistent luminescence nanoparticles (PLNPs) are promising luminescent materials that can store excitation energy and then slowly release the trapped charge carriers to emit persistent luminescence without continuous excitation. PLNPs alone have limited impact on cancer cells development ${ }^{108}$. In 2015, a novel X-ray inducible photodynamic therapy (X-PDT) approach was reported that allows PDT to be regulated by Xrays. Upon $\mathrm{X}$-ray irradiation, the integrated nanosystem, which corresponds to a core of a nanoscintillator $\mathrm{SrAl}_{2} \mathrm{O}_{4}: \mathrm{Eu}^{2+}(\mathrm{SAO})$ and a mesoporous silica coating loaded with photosensitizers (MW540) ${ }^{93}$, converts X-ray photons to visible photons to activate the photosensitizers and cause efficient tumor shrinkage (see Figure 9).

Fig. 9. Schematic of PLNPs loaded with PDT agent (MC540), adapted from ${ }^{93}$. 
In 2018, Yang and co-workers have shown that Zn (II) phthalocyanine tetrasulfonic acid ( $\mathrm{ZnPcS} 4)$ can be covalently linked to ZGO in order to fabricate PDT nanoplatform (ZGO:Cr/W-ZnPcS4). The persistent luminescence continously excites the coupled PS after the X-ray irradiation has been removed, resulting in significantly reduced $X$-ray dosage $(\approx 0.18 \mathrm{~Gy})$, minimizing the side effects of PDT treatment ${ }^{23 a}$.

\section{Photothermal therapy with PLNPs}

Among all the cancer treatments, near infrared (NIR $700 \mathrm{~nm}-1000 \mathrm{~nm}$ ) laser induced photothermal therapy (PTT) is a non-invasive mode that can generate heats at the tumors site ${ }^{109}$. Compared with conventional therapies, it has attracted much interest in tumor therapy as a minimally invasive and noninjurious therapeutic program as well as large penetration into bio-tissues. Photothermal therapy agents are capable of converting light energy into heat inducing a rise in the local temperature beyond $42{ }^{\circ} \mathrm{C}$ and killing consequently cancer cells. As a FDA-approved drug, indocyanine green (ICG) is attractive for localized hyperthermia by absorbing near-infrared light (around $800 \mathrm{~nm}$ ) even in deep tissue to generate heat. To further enhance the fluorescence stability and Enhanced Permeation and Retention effect (EPR) of ICG in-vivo, a variety of nanocarriers have been developed. Therefore, the ICG loading nanoparticle is a brand-new photothermal therapy agent which could be diffusely used in clinic for photothermal therapy. Nevertheless, the traditional ICG loading nanoparticles cannot be tracked when they circulate in the body, therefore it is out of the question to ensure an accurate irradiation with additional near infrared $(700 \mathrm{~nm}-1000 \mathrm{~nm})$ laser. Optical imaging-guided therapy has received great attention recently and become a fine choice of loading the ICG and tracking it for PTT ${ }^{110}$.

Fig. 10. PTT with ICG loaded PLNPs. Adapted from ${ }^{110}$.

Very recently in 2017, Chang and co-workers used ZGO NPs and ICG coloaded into mesoporous silica nanoparticles (ICG@mZGO nanoparticles) for imaging-guided PTT ${ }^{111}$. The ICG@mZGO nanoparticles consisted of two parts: i) The mesoporous $\mathrm{SiO}_{2} / \mathrm{ZnGa}_{2} \mathrm{O}_{4}: \mathrm{Cr}^{3+}$ (mZGO) near-infrared PLNPs were used as near-infrared emitting probe to track NPs in-vivo after excited by light. They found that mesoporous silica nanoparticles could be a fine template to synthesize ZGO phosphors in situ with good morphology 
and expected size. Mesoporous silica nanoparticles could also load and protect ICG, which had the ability to avoid particle aggregation effectively during the transportation; ii) Indocyanine green (ICG), a kind of tricarbocyanine dye, which substantially absorbed the near-infrared light (NIR) and in result returned a photothermal response.

In a different approach, upconverting PLNPs and photo-absorbing agents ICG co-loaded into $\mathrm{mSiO}_{2}$ (UC-PLNPs and ICG co-loaded $\mathrm{mSiO}_{2}$ ) nanoparticles were developed for upconverting and persistent luminescent imaging guided PTT ${ }^{52}$. The UCPLNPs and ICG co-loaded $\mathrm{mSiO}_{2}$ nanoparticles include three parts: i) the upconverting PLNPs, doped with $\mathrm{Pr}^{3+}, \mathrm{Er}^{3+}$ and $\mathrm{Tm}^{3+}$ chosen for upconverting and persistent luminescent imaging. These NPs could be excited by NIR light and emit upconverting luminescence, which can be used for in-vivo imaging when the persistent luminescence signal became weak; ii) the ICG (indocyanine green), a water soluble anionic tricarbocyanine dye which is the only NIR agent approved by FDA and which has been widely used clinically for PTT; iii) the mesoporous silica nanoparticles working as a three dimension hard template for loading and protecting both upconverting PLNPs and ICG ${ }^{52}$.

\section{Perspectives of the NIR-persistent luminescent nanoparticles for bio- imaging}

Firstly, to move the persistent emission wavelength to the second and third biological windows (see Figure 11-C) and compared the pro and drawbacks of such strategy, different approaches are currently explored: i) Traps can be coupled to various rare earth cations $\left(\mathrm{Yb}^{3+}, \mathrm{Nd}^{3+}, \mathrm{Er}^{3+}, \mathrm{Ho}^{3+}, \mathrm{Tm}^{3+}\right.$ or even $\mathrm{Pr}^{3+}$ ) well known in the case of NIR lasers (see Fig 11-(B)) ${ }^{112}$. ii) Down shifting can also be obtained by coupling different rare earth cations or metal transition (MT) and rare earth cations. The so-call traps redistribution by energy transfer can downshift the persistent emission wavelengths (see Fig 11-(A)). Such down-conversion processes were proposed recently for garnet and perovskite hosts coupling metal transition cation $\left(\mathrm{Cr}^{3+}\right)$ with rare earth cations to promote by persistent energy transfer the persistent luminescence in the deep red (from $\mathrm{Cr}^{3+}$ ) but also in the second or third biological windows (results were obtained with $\mathrm{Yb}^{3+}, \mathrm{Nd}^{3+}, \mathrm{Er}^{3+}, \mathrm{Ho}^{3+}$ ions) ${ }^{47,113}$. iii) Transition metal cations such as $\mathrm{Ni}^{2+}$ or $\mathrm{Co}^{2+}$ were also recently investigated ${ }^{114}$ (see Fig 11-(D)) to cover the second biological window and these MT cations have also large potential. Indeed, recently, Qiu and co-workers reported a 
strategy for tuning the emission bandwidth and intensity in persistent luminescence phosphors by synthetizing $\mathrm{Ni}^{2+}$-doped $\mathrm{Zn}_{1+\mathrm{y}} \mathrm{Sn}_{\mathrm{y}} \mathrm{Ga}_{2-\mathrm{x}-2 \mathrm{y}} \mathrm{O}_{4}$ phosphors, with an emission band peaking from 1270 to $1430 \mathrm{~nm}$ in the second near-infrared (NIR) window ${ }^{115}$. Ueda ${ }^{116}$ and Tanabe ${ }^{117}$ and our groups also reported compositions able to be used in the second transparency window $114 \mathrm{a}$.

Fig. 11. : (A) trap redistribution and persistent energy transfer in metal transition $(\mathrm{Cr})$ and rare earth doped garnet ${ }^{47},(B)$ Trivalent rare earth cations as efficient emitters for short wave infrared persistent luminescence $^{112}$, (C) Optical window in biological tissues; high: attenuation coefficient (log) as a function of the wavelength. Bottom: sensitivity of different cameras (silicon ( $\mathrm{Si}$ ) cameras, indium gallium arsenide (InGaAs) or mercury cadmium telluride $(\mathrm{HgCdTe}))^{118}$ and $(\mathrm{D})$ : optical features and persistent luminescence of $\mathrm{ZnGa}_{2} \mathrm{O}_{4}: \mathrm{Ni}$ and $\mathrm{Zn}(\mathrm{GeGa})_{2} \mathrm{O}_{4}: \mathrm{Ni}$. Decay profiles and scheme of excitation, adapted from ${ }^{114 a}$

Secondly, moving to the second and third near-infrared transparency windows (1000 nm - $1700 \mathrm{~nm}$ ) allows further reducing of scattering, absorption and tissue autofluorescence effects. Moreover, if the quantum efficiency values, for $\mathrm{Si}$, InGaAs (and $\mathrm{HgCdTe}$ ) can be comparable, the acquisition time is also to be taken into account. For a CCD camera the dark current is of the order a few electron/pixel/hour and it is about $100 \mathrm{ke} / \mathrm{pixel} / \mathrm{s}$ for InGaAs. The readout noise has also to be taken into account (see values in Table 3). By the end, the signal is one to two orders of magnitude smaller for InGaAs detector (and $\mathrm{HgCdTe}$ ) in the NIR range with respect to the $\mathrm{Si}$ detector in BW-1. Imaging platforms then require the use of powerful and cooled cameras.

Table 3: Characteristics of the NIR and deep-red sensors

\begin{tabular}{lll}
\hline & 1.5 micron NIR camera & Visible camera \\
\hline Material type & InGaAs & Si/CMOS \\
\hline Quantum efficiency & $80 \%$ & $80 \%$ \\
Readout noise & about $30 \mathrm{e}^{-}$ & about $1 \mathrm{e}^{-}$ \\
Dark current & $100 \mathrm{ke} / \mathrm{pixels} / \mathrm{s}$ & $<0.5 \mathrm{e}^{-/ \mathrm{pixels} / \mathrm{s}}$ \\
Pixel size & About 15 micrometers & About 4 micrometers \\
\hline
\end{tabular}

Then the balance between benefit and drawbacks for these two aspects related to the second and third biological windows remains to be explored. In a decade, persistent luminescence has emerged as a useful property for the development of new optical imaging nanoprobes. Thanks to this property of 
long lasting luminescence, imaging in the first transparency window (NIRI) with high target to background ratio has been reported by several research groups (more than 40 research groups all over the world and more than 200 papers published in the last ten years). Beyond to their uses for imaging and therapy, new applications emerged. We can cite for instance their use for the development of nanothermometers. For this purpose, the idea is to use the luminescence emitted by nanoprobes to detect temperature variations at the nanoscale ${ }^{11936}$.

\section{Conclusions}

Very recent and promising works on persistent luminescence nanoparticles concern the development of biocompatible nanoprobes for multimodal imaging, theranostics and drug delivery, photodynamic and photothermal therapies, nanothermometry and hyperthermia etc. These PLNPs were even recently proposed as a guide during surgery operation to accurate delineation of hepatocellular carcinoma ${ }^{120}$.

Then, one of the next challenge will be: can these PLNPs be used at wavelengths longer than $1000 \mathrm{~nm}$ ?. Indeed, optical imaging in the second nearinfrared region (NIR-II, 1.0-1.7 $\mu \mathrm{m}$ ) has recently attracted significant attention owing to some advantages : if the ballistic light (without diffusion) and the so-call "snake" light with limited diffusion remain about the same, the diffuse light with all the information is lost can be very limited moving in that NIR range. Photons in the NIR-II region can provide high spatial resolution at deep tissue penetration depths owing to the reduced scattering of long-wavelength photons ${ }^{121}$. Furthermore, imaging in the second near-infrared region addresses several challenges simultaneously: minimal autofluorescence of biological tissue leading to increased sensitivity and significantly reduced light attenuation from scattering and from absorption by the blood and other structures enables imaging with high spatiotemporal resolution and penetration depth ${ }^{122}$. Consequently, large organisms such as a whole mouse may be rendered translucent when imaged in this area ${ }^{123}$. The image reconstruction is also a very important work as was done for instance in the acousto-optic images ${ }^{124}$.

Nevertheless there is still several others challenges for the scientific community such as, the synthesis of long circulating "stealth" nanomaterials, the functionalization with targeting agents prerequisite for PLNPs later use. Others important requirements are to keep a high intensity at the nanoscale, and to well control the surface properties in order to stabilize the PLNPs in 
different biological media. Then, with the nano-objects, imagination will be the only limit to the use and applications of these fascinating nanoparticles.

\section{Acknowledgments}

This work was supported by the French national research agency (ANR Natlurim and ANR PEPSI 14-CE08-0016-01), by a grant from the Pres Sorbonne Paris-Cité (ODICEO project), by CNRS, by Biospace Lab, by the PRC Japon JSPS/French Bilateral grant (PRC1248) and by PHC Procore (33122PA). The authors acknowledge their collaborators: Q. le Masne de Chermont, T. Maldiney, E. Teston, G. Ramirez-Garcia, T. Lecuyer, J. Seguin, D. Scherman, D. Gourier, A. Bessière, L. Binet, M. Allix, S. Sharma, S. Tanabe, F. Gazeau and L. Laumonier.

\section{References}

1. Matsuzawa, T.; Aoki, Y.; Takeuchi, N.; Murayama, Y., New long phosphorescent phosphor with high brightness, SrA12O4:Eu2+,Dy3+. Journal of the Electrochemical Society 1996, 143 (8), 2670-2673.

2. (a) Van den Eeckhout, K.; Smet, P. F.; Poelman, D., Persistent Luminescence in Eu2+-Doped Compounds: A Review. Materials 2010, 3 (4), 25362566; (b) Van den Eeckhout, K.; Poelman, D.; Smet, P. F., Persistent Luminescence in Non-Eu2+-Doped Compounds: A Review. Materials 2013, 6 (7), 2789-2818.

3. (a) Viana, B.; Sharma, S. K.; Gourier, D.; Maldiney, T.; Teston, E.; Scherman, D.; Richard, C., Long term in vivo imaging with Cr3+ doped spinel nanoparticles exhibiting persistent luminescence. Journal of Luminescence 2016, 170, 879-887; (b) Lécuyer, T.; Teston, E.; Ramirez-Garcia, G.; Maldiney, T.; Viana, B.; Seguin, J.; Mignet, N.; Scherman, D.; Richard, C., Chemically engineered persistent luminescence nanoprobes for bioimaging. Theranostics 2016, 6 (13), 2488; (c) Jaque, D.; Richard, C.; Viana, B.; Soga, K.; Liu, X. G.; Sole, J. G., Inorganic nanoparticles for optical bioimaging. Advances in Optics and Photonics 2016, 8 (1), 1-103; (d) Sharma, S. K.; Gourier, D.; Viana, B.; Maldiney, T.; Teston, E.; Scherman, D.; Richard, C., Persistent luminescence of $\mathrm{AB}(2) \mathrm{O}(4): \mathrm{Cr} 3+(\mathrm{A}=$ $\mathrm{Zn}, \mathrm{Mg}, \mathrm{B}=\mathrm{Ga}, \mathrm{Al})$ spinels: New biomarkers for in vivo imaging. Optical Materials 2014, 36 (11), 1901-1906; (e) Maldiney, T.; Bessiere, A.; Seguin, J.; Teston, E.; Sharma, S. K.; Viana, B.; Bos, A. J. J.; Dorenbos, P.; Bessodes, M.; Gourier, D.; Scherman, D.; Richard, C., The in vivo activation of persistent nanophosphors for optical imaging of vascularization, tumours and grafted cells. Nature Materials 2014, 13 (4), 418-426; (f) Maldiney, T.; Sraiki, G.; Viana, B.; Gourier, D.; Richard, C.; Scherman, D.; Bessodes, M.; Van den Eeckhout, K.; Poelman, D.; Smet, P. F., In vivo optical imaging with rare earth doped Ca2Si5N8 
persistent luminescence nanoparticles. Optical Materials Express 2012, 2 (3), 261268.

4. Hillman, E. M. C.; Amoozegar, C. B.; Wang, T.; McCaslin, A. F. H.; Bouchard, M. B.; Mansfield, J.; Levenson, R. M., In vivo optical imaging and dynamic contrast methods for biomedical research. Philosophical Transactions of the Royal Society a-Mathematical Physical and Engineering Sciences 2011, 369 (1955), 4620-4643.

5. de Jong, M.; Essers, J.; van Weerden, W. M., Imaging preclinical tumour models: improving translational power. Nature Reviews Cancer 2014, 14 (7), 481493.

6. Huang, Y.-Y., Hamblin, M., Chen, A.C.-H., 2009. Low-level laser therapy: an emerging clinical paradigm. SPIE Newsroom. http://dx.doi.org/10.1117/2.1200906.1669

7. S. J. Matcher, M. Cope, and D. T. Delpy, In vivo measurements of the wavelength dependence of tissue scattering coefficients between 760 and $900 \mathrm{~nm}$ measured with time-resolved spectroscopy, Applied Optics, 1997, 36, 386-396

8. H. Yukawa, M. Watanabe, N. Kaji, Y. Baba, Influence of Autofluorescence Derived From Living Body on In Vivo Fluorescence Imaging Using Quantum Dots, Cell Medicine, 2015, 7, 75-82

9. Jaque, D.; Richard, C.; Viana, B.; Soga, K.; Liu, X.; Solé, J. G., Inorganic nanoparticles for optical bioimaging. Advances in Optics and Photonics 2016, 8 (1), $1-103$.

10. (a) Holsa, J.; Aitasalo, T.; Jungner, H.; Lastusaari, M.; Niittykoski, J.; Spano, G., Role of defect states in persistent luminescence materials. Journal of Alloys and Compounds 2004, 374 (1-2), 56-59; (b) Holsa, J.; Laamanen, T.; Lastusaari, M.; Malkamaki, M.; Novak, P., Persistent luminescence - Quo vadis? Journal of Luminescence 2009, 129 (12), 1606-1609.

11. Maldiney, T.; Bessière, A.; Seguin, J.; Teston, E.; Sharma, S. K.; Viana, B.; Bos, A. J.; Dorenbos, P.; Bessodes, M.; Gourier, D., The in vivo activation of persistent nanophosphors for optical imaging of vascularization, tumours and grafted cells. Nature materials 2014, 13 (4), 418-426.

12. (a) Aitasalo, T.; Deren, P.; Holsa, J.; Jungner, H.; Krupa, J. C.; Lastusaari, M.; Legendziewicz, J.; Niittykoski, J.; Strek, W., Persistent luminescence phenomena in materials doped with rare earth ions. Journal of Solid State Chemistry 2003, 171 (1-2), 114-122; (b) Dorenbos, P., Mechanism of persistent luminescence in Eu2+ and Dy3+ codoped aluminate and silicate compounds. Journal of the Electrochemical Society 2005, 152 (7), H107-H110.

13. Bessiere, A.; Jacquart, S.; Priolkar, K.; Lecointre, A.; Viana, B.; Gourier, D., ZnGa2O4:Cr3+: a new red long-lasting phosphor with high brightness. Optics Express 2011, 19 (11), 10131-10137.

14. C. Rosticher, C. Chanéac, B. Viana, M. A. Fortin, J. Lagueux, L. Faucher, "Red Persistent luminescence and magnetic properties of nanomaterials for multimodal imaging" SPIE, Oxide-based Materials and Devices VI, OE108, in press (2015)

15. C. Rosticher, C. Chanéac, B. Viana, M. A. Fortin, J. Lagueux, L. Faucher, "Red Persistent luminescence and magnetic properties of nanomaterials for 
multimodal imaging" SPIE, Oxide-based Materials and Devices VI, OE108, in press (2015)

16. (a) Sun, M.; Li, Z.-J.; Liu, C.-L.; Fu, H.-X.; Shen, J.-S.; Zhang, H.-W., Persistent luminescent nanoparticles for super-long time in vivo and in situ imaging with repeatable excitation. Journal of Luminescence 2014, 145, 838-842; (b) Zeng, P.; Wei, X. T.; Yin, M.; Chen, Y. H., Investigation of the long afterglow mechanism in SrAl2O4:Eu2+/Dy3+ by optically stimulated luminescence and thermoluminescence. Journal of Luminescence 2018, 199, 400-406.

17. (a) de Chermont, Q. 1. M.; Chaneac, C.; Seguin, J.; Pelle, F.; Maitrejean, S.; Jolivet, J.-P.; Gourier, D.; Bessodes, M.; Scherman, D., Nanoprobes with nearinfrared persistent luminescence for in vivo imaging. Proceedings of the National Academy of Sciences of the United States of America 2007, 104 (22), 9266-9271; (b) Maldiney, T.; Richard, C.; Seguin, J.; Wattier, N.; Bessodes, M.; Scherman, D., Effect of Core Diameter, Surface Coating, and PEG Chain Length on the Biodistribution of Persistent Luminescence Nanoparticles in Mice. Acs Nano 2011, 5 (2), 854-862; (c) Maldiney, T.; Kaikkonen, M. U.; Seguin, J.; de Chermont, Q. 1. M.; Bessodes, M.; Airenne, K. J.; Yla-Herttuala, S.; Scherman, D.; Richard, C., In Vitro Targeting of Avidin-Expressing Glioma Cells with Biotinylated Persistent Luminescence Nanoparticles. Bioconjugate Chemistry 2012, 23 (3), 472-478.

18. Sun, S. K.; Wang, H. F.; Yan, X. P., Engineering Persistent Luminescence Nanoparticles for Biological Applications: From Biosensing/Bioimaging to Theranostics. Accounts of Chemical Research 2018, 51 (5), 1131-1143.

19. Maldiney, T.; Lecointre, A.; Viana, B.; Bessiere, A.; Bessodes, M.; Gourier, D.; Richard, C.; Scherman, D., Controlling Electron Trap Depth To Enhance Optical Properties of Persistent Luminescence Nanoparticles for In Vivo Imaging. Journal of the American Chemical Society 2011, 133 (30), 11810-11815. 20. Liu, J. M.; Liu, Y. Y.; Zhang, D. D.; Fang, G. Z.; Wang, S., Synthesis of GdAlO3:Mn4+,Ge4+@Au Core-Shell Nanoprobes with Plasmon-Enhanced NearInfrared Persistent Luminescence for in Vivo Trimodality Bioimaging. Acs Applied Materials \& Interfaces 2016, 8 (44), 29939-29949.

21. Li, J. L.; Wang, C. C.; Shi, J. P.; Li, P. H.; Yu, Z. F.; Zhang, H. W., Porous GdAlO3: $\mathrm{Cr} 3+, \mathrm{Sm} 3+$ drug carrier for real-time long afterglow and magnetic resonance dual-mode imaging. Journal of Luminescence 2018, 199, 363-371.

22. Sharma, S. K.; Gourier, D.; Viana, B.; Maldiney, T.; Teston, E.; Scherman, D.; Richard, C.; rajani, r. R., Persistent luminescence of $\mathrm{AB}(2) \mathrm{O}(4): \mathrm{Cr} 3+(\mathrm{A}=\mathrm{Zn}$, $\mathrm{Mg}, \mathrm{B}=\mathrm{Ga}, \mathrm{Al})$ spinels: New biomarkers for in vivo imaging. Optical Materials 2014, 36 (11), 1901-1906.

23. (a) Song, L.; Li, P. P.; Yang, W.; Lin, X. H.; Liang, H.; Chen, X. F.; Liu, G.; Li, J.; Yang, H. H., Low-Dose X-ray Activation of W(VI)-Doped Persistent Luminescence Nanoparticles for Deep-Tissue Photodynamic Therapy. Advanced Functional Materials 2018, 28 (18); (b) Xue, Z. L.; Li, X. L.; Li, Y. B.; Jiang, M. Y.; Liu, H. R.; Zeng, S. J.; Hao, J. H., X-ray-Activated Near-Infrared Persistent Luminescent Probe for Deep-Tissue and Renewable in Vivo Bioimaging. Acs Applied Materials \& Interfaces 2017, 9 (27), 22132-22142.

24. Liu, H. H.; Ren, F.; Zhang, H.; Han, Y. B.; Qin, H. Z.; Zeng, J. F.; Wang, Y.; Sun, Q.; Li, Z.; Gao, M. Y., Oral administration of highly bright Cr3+ doped 
$\mathrm{ZnGa2O} 4$ nanocrystals for \&ITin vivo \&ITtargeted imaging of orthotopic breast cancer. Journal of Materials Chemistry B 2018, 6 (10), 1508-1518.

25. Ramirez-Garcia, G.; Gutierrez-Granados, S.; Gallegos-Corona, M. A.; Palma-Tirado, L.; d'Orlye, F.; Varenne, A.; Mignet, N.; Richard, C.; MartinezAlfaro, M., Long-term toxicological effects of persistent luminescence nanoparticles after intravenous injection in mice. International Journal of Pharmaceutics 2017, 532 (2), 686-695.

26. Liu, Y. Y.; Liu, J. M.; Zhang, D. D.; Ge, K.; Wang, P. H.; Liu, H. L.; Fang, G. Z.; Wang, S., Persistent Luminescence Nanophosphor Involved Near-Infrared Optical Bioimaging for Investigation of Foodborne Probiotics Biodistribution in Vivo: A Proof-of-Concept Study. Journal of Agricultural and Food Chemistry 2017, 65 (37), 8229-8240.

27. Wang, J.; Li, J. L.; Yu, J. N.; Zhang, H. W.; Zhang, B. B., Large Hollow Cavity Luminous Nanoparticles with Near-Infrared Persistent Luminescence and Tunable Sizes for Tumor Afterglow Imaging and Chemo-/Photodynamic Therapies. Acs Nano 2018, 12 (5), 4246-4258.

28. Maldiney, T.; Doan, B.-T.; Alloyeau, D.; Bessodes, M.; Scherman, D.; Richard, C., Gadolinium-Doped Persistent Nanophosphors as Versatile Tool for Multimodal In Vivo Imaging. Advanced Functional Materials 2015, 25 (2), 331338.

29. Maldiney, T.; Ballet, B.; Bessodes, M.; Scherman, D.; Richard, C., Mesoporous persistent nanophosphors for in vivo optical bioimaging and drugdelivery. Nanoscale 2014, 6 (22), 13970-13976.

30. Teston, E.; Maldiney, T.; Marangon, I.; Volatron, J.; Lalatonne, Y.; Motte, L.; Boisson-Vidal, C.; Autret, G.; Clement, O.; Scherman, D.; Gazeau, F.; Richard, C., Nanohybrids with Magnetic and Persistent Luminescence Properties for Cell Labeling, Tracking, In Vivo Real-Time Imaging, and Magnetic Vectorization. Small 2018, 14 (16).

31. Zou, R.; Gong, S. M.; Shi, J. P.; Jiao, J.; Wong, K. L.; Zhang, H. W.; Wang, J.; Su, Q., Magnetic-NIR Persistent Luminescent Dual-Modal ZGOCS@MSNs@Gd2O3 Core-Shell Nanoprobes For In Vivo Imaging. Chemistry of Materials 2017, 29 (9), 3938-3946.

32. Shi, J.; Sun, X.; Li, J.; Man, H.; Shen, J.; Yu, Y.; Zhang, H., Multifunctional near infrared-emitting long-persistence luminescent nanoprobes for drug delivery and targeted tumor imaging. Biomaterials 2015, 37, 260-270.

33. Li, Y.; Zhou, S.; Dong, G.; Peng, M.; Wondraczek, L.; Qiu, J., Anti-Stokes Fluorescent Probe with Incoherent Excitation. Scientific Reports 2014, 4.

34. Liu, J. M.; Zhang, D. D.; Fang, G. Z.; Wang, S., Erythrocyte membrane bioinspired near-infrared persistent luminescence nanocarriers for in vivo longcirculating bioimaging and drug delivery. Biomaterials 2018, 165, 39-47.

35. Li, Y. J.; Yang, C. X.; Yan, X. P., Biomimetic Persistent Luminescent Nanoplatform for Autofluorescence-Free Metastasis Tracking and Chemophotodynamic Therapy. Analytical Chemistry 2018, 90 (6), 4188-4195.

36. Yang, J.; Liu, Y. X.; Zhao, Y. Y.; Gong, Z.; Zhang, M.; Yan, D. T.; Zhu, H. C.; Liu, C. G.; Xu, C. S.; Zhang, H., Ratiometric Afterglow Nanothermometer 
for Simultaneous in Situ Bioimaging and Local Tissue Temperature Sensing. Chemistry of Materials 2017, 29 (19), 8119-8131.

37. Li, Y.; Zhou, S.; Li, Y.; Sharafudeen, K.; Ma, Z.; Dong, G.; Peng, M.; Qiu, J., Long persistent and photo-stimulated luminescence in $\mathrm{Cr} 3+$-doped $\mathrm{Zn}-\mathrm{Ga}-\mathrm{Sn}-\mathrm{O}$ phosphors for deep and reproducible tissue imaging. Journal of Materials Chemistry C 2014, 2 (15), 2657-2663.

38. Abdukayum, A.; Chen, J.-T.; Zhao, Q.; Yan, X.-P., Functional Near Infrared-Emitting $\mathrm{Cr} 3+/ \mathrm{Pr} 3+$ Co-Doped Zinc Gallogermanate Persistent Luminescent Nanoparticles with Superlong Afterglow for in Vivo Targeted Bioimaging. Journal of the American Chemical Society 2013, 135 (38), 1412514133.

39. Li, J.; Shi, J.; Shen, J.; Man, H.; Wang, M.; Zhang, H., Specific Recognition of Breast Cancer Cells In Vitro Using Near Infrared-Emitting LongPersistence Luminescent Zn3Ga2Ge2O10:Cr3+ Nanoprobes. Nano-Micro Letters 2015, 7 (2), 138-145.

40. Liu, F.; Liang, Y.; Pan, Z., Detection of Up-converted Persistent Luminescence in the Near Infrared Emitted by the Zn3Ga2GeO8: Cr3(+), Yb3+, Er3+ Phosphor. Physical Review Letters 2014, 113 (17).

41. (a) Fu, X.; Liu, C.; Shi, J.; Man, H.; Xu, J.; Zhang, H., Long persistent near infrared luminescence nanoprobes LiGa5O8:Cr3+-PEG-OCH3 for in vivo imaging. Optical Materials 2014, 36 (11), 1792-1797; (b) Liu, F.; Yan, W.; Chuang, Y.-J.; Zhen, Z.; Xie, J.; Pan, Z., Photostimulated near-infrared persistent luminescence as a new optical read-out from Cr3+-doped LiGa5O8. Scientific Reports 2013, 3.

42. Chen, D.; Chen, Y.; Lu, H.; Ji, Z., A Bifunctional $\mathrm{Cr} / \mathrm{Yb} / \mathrm{Tm}: \mathrm{Ca} 3 \mathrm{Ga} 2 \mathrm{Ge} 3 \mathrm{O} 12$ Phosphor with Near-Infrared Long-Lasting Phosphorescence and Upconversion Luminescence. Inorganic Chemistry 2014, 53 (16), 8638-8645.

43. Dai, W. B.; Lei, Y. F.; Zhou, J.; Xu, M.; Chu, L. L.; Li, L.; Zhao, P.; Zhang, Z. H., Near-infrared quantum-cutting and long-persistent phosphor Ca3Ga2Ge3O12: Pr3+, Yb3+ for application in \&ITin vivo\&IT bioimaging and dye-sensitized solar cells. Journal of Alloys and Compounds 2017, 726, 230-239.

44. Shi, J. P.; Sun, X.; Zheng, S. H.; Li, J. L.; Fu, X. Y.; Zhang, H. W., A new near-infrared persistent luminescence nanoparticle as a multifunctional nanoplatform for multimodal imaging and cancer therapy. Biomaterials 2018, 152, $15-23$.

45. Kamimura, S.; Xu, C.-N.; Yamada, H.; Terasaki, N.; Fujihala, M., Longpersistent luminescence in the near-infrared from Nd3+-doped $\mathrm{Sr} 2 \mathrm{SnO} 4$ for in vivo optical imaging. Japanese Journal of Applied Physics 2014, 53 (9).

46. Li, Z.; Shi, J.; Zhang, H.; Sun, M., Highly controllable synthesis of nearinfrared persistent luminescence $\mathrm{SiO} / \mathrm{CaMgSi} 2 \mathrm{O} 6$ composite nanospheres for imaging in vivo. Optics Express 2014, 22 (9), 10509-10518.

47. Xu, J.; Murata, D.; Ueda, J.; Viana, B.; Tanabe, S., Toward Rechargeable Persistent Luminescence for the First and Third Biological Windows via Persistent Energy Transfer and Electron Trap Redistribution. Inorganic Chemistry 2018, 57 (9), 5194-5203. 
48. Hu, L. D.; Wang, P. Y.; Zhao, M. Y.; Liu, L.; Zhou, L.; Li, B. H.; Albaqami, F. H.; El-Toni, A. M.; Li, X. M.; Xie, Y.; Sun, X. F.; Zhang, F., Nearinfrared rechargeable "optical battery" implant for irradiation-free photodynamic therapy. Biomaterials 2018, 163, 154-162.

49. Homayoni, H.; Ma, L.; Zhang, J. Y.; Sahi, S. K.; Rashidi, L. H.; Bui, B.; Chen, W., Synthesis and conjugation of Sr2MgSi2O7:Eu2+, Dy3+ water soluble afterglow nanoparticles for photodynamic activation. Photodiagnosis and Photodynamic Therapy 2016, 16, 90-99.

50. Y Yu, Z. Z.; Liu, B.; Pan, W.; Zhang, T. T.; Tong, L. L.; Li, N.; Tang, B., A simple approach for glutathione functionalized persistent luminescence nanoparticles as versatile platforms for multiple in vivo applications. Chemical Communications 2018, 54 (28), 3504-3507.

51. Zhan, D. D.; Liu, J. M.; Song, N.; Liu, Y. Y.; Dang, M.; Fang, G. Z.; Wang, S., Fabrication of mesoporous La3Ga5GeO14:Cr3+,Zn2+ persistent luminescence nanocarriers with super-long afterglow for bioimaging-guided \&ITin vivo \&ITdrug delivery to the gut. Journal of Materials Chemistry B 2018, 6 (10), 1479-1488.

52. Zhao, P. Q.; Ji, W.; Zhou, S. Y.; Qiu, L. H.; Li, L. F.; Qian, Z. Z.; Liu, X. M.; Zhang, H. L.; Cao, X. C., Upconverting and persistent luminescent nanocarriers for accurately imaging-guided photothermal therapy. Materials Science \& Engineering C-Materials for Biological Applications 2017, 79, 191-198.

53. Li, J. L.; Shi, J. P.; Wang, C. C.; Li, P. H.; Yu, Z. F.; Zhang, H. W., Fivenanometer $\mathrm{ZnSn2O} 4$ : Cr, Eu ultra-small nanoparticles as new near infrared-emitting persistent luminescent nanoprobes for cellular and deep tissue imaging at $800 \mathrm{~nm}$. Nanoscale 2017, 9 (25), 8631-8638.

54. Kamimura, S.; Xu, C. N.; Yamada, H.; Marriott, G.; Hyodo, K.; Ohno, T., Near-infrared luminescence from double-perovskite Sr3Sn2O7:Nd3+: A new class of probe for in vivo imaging in the second optical window of biological tissue. Journal of the Ceramic Society of Japan 2017, 125 (7), 591-595.

55. Brito, H. F.; Holsa, J.; Laamanen, T.; Lastusaari, M.; Malkamaki, M.; Rodrigues, L. C. V., Persistent luminescence mechanisms: human imagination at work. Optical Materials Express 2012, 2 (4), 371-381.

56. (a) Viana, B.; Sharma, S.; Gourier, D.; Maldiney, T.; Teston, E.; Scherman, D.; Richard, C., Long term in vivo imaging with $\mathrm{Cr} 3+$ doped spinel nanoparticles exhibiting persistent luminescence. Journal of Luminescence 2016, 170, 879-887; (b) Singh, S. K., Red and near infrared persistent luminescence nano-probes for bioimaging and targeting applications. Rsc Advances 2014, 4 (102), 58674-58698. 57. Smith, A. M.; Mancini, M. C.; Nie, S., BIOIMAGING Second window for in vivo imaging. Nature Nanotechnology 2009, 4 (11), 710-711.

58. Stanek, C. R.; Jiang, C.; Yadav, S. K.; McClellan, K. J.; Uberuaga, B. P.; Andersson, D. A.; Nikl, M., The effect of Ga-doping on the defect chemistry of RE3Al5O12 garnets. Physica Status Solidi B-Basic Solid State Physics 2013, 250 (2), 244-248.

59. (a) Bessiere, A.; Sharma, S. K.; Basavaraju, N.; Priolkar, K. R.; Binet, L.; Viana, B.; Bos, A. J. J.; Maldiney, T.; Richard, C.; Scherman, D.; Gourier, D., Storage of Visible Light for Long-Lasting Phosphorescence in Chromium-Doped Zinc Gallate. Chemistry of Materials 2014, 26 (3), 1365-1373; (b) Zhuang, Y.; 
Ueda, J.; Tanabe, S.; Dorenbos, P., Band-gap variation and a self-redox effect induced by compositional deviation in $\mathrm{ZnxGa} 2 \mathrm{O} 3+\mathrm{x}: \mathrm{Cr} 3+$ persistent phosphors. Journal of Materials Chemistry C 2014, 2 (28), 5502-5509.

60. Blahuta, S.; Bessiere, A.; Viana, B.; Ouspenski, V.; Mattmann, E.; Lejay, J.; Gourier, D., Defects Identification and Effects of Annealing on Lu2(1$\mathrm{x}) \mathrm{Y} 2 \mathrm{xSiO} 5$ (LYSO) Single Crystals for Scintillation Application. Materials 2011, 4 (7), 1224-1237.

61. (a) Ueda, J.; Kuroishi, K.; Tanabe, S., Development of blue excitable persistent phosphor of $\mathrm{Ce} 3+$-doped garnet ceramics by bandgap engineering and metal sensitization. Oxide-Based Materials and Devices $V$ 2014, 8987; (b) Katayama, Y.; Kayumi, T.; Ueda, J.; Tanabe, S., Enhanced persistent red luminescence in $\mathrm{Mn} 2+$-doped $(\mathrm{Mg}, \mathrm{Zn}) \mathrm{GeO} 3$ by electron trap and conduction band engineering. Optical Materials 2018, 79, 147-151.

62. (a) Dorenbos, P., Lanthanide 4f-electron binding energies and the nephelauxetic effect in wide band gap compounds. Journal of Luminescence 2013, 136, 122-129; (b) Dorenbos, P., Electronic structure and optical properties of the lanthanide activated RE3(Al1-xGax)(5)O-12 $(\mathrm{RE}=\mathrm{Gd}, \mathrm{Y}, \mathrm{Lu})$ garnet compounds. Journal of Luminescence 2013, 134, 310-318.

63. Kunkel, N.; Sontakke, A. D.; Kohaut, S.; Viana, B.; Dorenbos, P., Thermally Stimulated Luminescence and First-Principle Study of Defect Configurations in the Perovskite-Type Hydrides LiMH3:Eu2+ $(\mathrm{M}=\mathrm{Sr}, \mathrm{Ba})$ and the Corresponding Deuterides. The Journal of Physical Chemistry C 2016, 120 (51), 29414-29422.

64. Sharma, S. K.; Bessiere, A.; Basavaraju, N.; Priolkar, K. R.; Binet, L.; Viana, B.; Gourier, D., Interplay between chromium content and lattice disorder on persistent luminescence of $\mathrm{ZnGa} 2 \mathrm{O} 4: \mathrm{Cr}-3$ for in vivo imaging. Journal of Luminescence 2014, 155, 251-256.

65. Korthout, K.; Van den Eeckhout, K.; Botterman, J.; Nikitenko, S.; Poelman, D.; Smet, P. F., Luminescence and X-ray absorption measurements of persistent SrA12O4:Eu,Dy powders: Evidence for valence state changes. Physical Review B 2011, 84 (8).

66. (a) Ueda, J.; Tanabe, S.; Nakanishi, T., Analysis of Ce3+ luminescence quenching in solid solutions between $\mathrm{Y} 3 \mathrm{~A} 15 \mathrm{O} 12$ and $\mathrm{Y} 3 \mathrm{Ga} 5 \mathrm{O} 12$ by temperature dependence of photoconductivity measurement. Journal of Applied Physics 2011, 110 (5); (b) Lecointre, A.; Bessiere, A.; Bos, A. J. J.; Dorenbos, P.; Viana, B.; Jacquart, S., Designing a Red Persistent Luminescence Phosphor: The Example of YPO4:Pr3+, Ln(3+) $(\mathrm{Ln}=\mathrm{Nd}$, Er, Ho, Dy). Journal of Physical Chemistry C 2011, 115 (10), 4217-4227.

67. Casillas-Trujillo, L.; Andersson, D. A.; Dorado, B.; Nikl, M.; Sickafus, K. E.; McClellan, K. J.; Stanek, C. R., Intrinsic defects, nonstoichiometry, and aliovalent doping of $\mathrm{A}(2+) \mathrm{B}(4)+\mathrm{O}-3$ perovskite scintillators. Physica Status Solidi B-Basic Solid State Physics 2014, 251 (11), 2279-2286.

68. (a) Bessiere, A.; Lecointre, A.; Benhamou, R. A.; Suard, E.; Wallez, G.; Viana, B., How to induce red persistent luminescence in biocompatible Ca3(PO4)(2). Journal of Materials Chemistry C 2013, 1 (6), 1252-1259; (b) Bos, A. 
J. J.; Dorenbos, P.; Bessiere, A.; Viana, B., Lanthanide energy levels in YPO4. Radiation Measurements 2008, 43 (2-6), 222-226.

69. Van den Eeckhout, K.; Bos, A. J. J.; Poelman, D.; Smet, P. F., Revealing trap depth distributions in persistent phosphors. Physical Review B 2013, 87 (4).

70. Chuang, Y.-J.; Zhen, Z.; Zhang, F.; Liu, F.; Mishra, J. P.; Tang, W.; Chen, H.; Huang, X.; Wang, L.; Chen, X.; Xie, J.; Pan, Z., Photostimulable Near-Infrared Persistent Luminescent Nanoprobes for Ultrasensitive and Longitudinal DeepTissue Bio-Imaging. Theranostics 2014, 4 (11), 1112-1122.

71. Botterman, J.; Van den Eeckhout, K.; De Baere, I.; Poelman, D.; Smet, P. F., Mechanoluminescence in BaSi2O2N2:Eu. Acta Materialia 2012, 60 (15), 54945500 .

72. E. Glais, M. Pellerin, D. Alloyeau, N.Touati, B. Viana, C. Chanéac, submitted in sensors and actuators B, [2018]

73. Victor, C.; D., S. A.; José, F.-C. A.; Nadia, T.; Laurent, B.; Mathieu, A.; Didier, G.; Bruno, V., Persistent Luminescence of ZnGa2O4:Cr3+ Transparent Glass Ceramics: Effects of Excitation Wavelength and Excitation Power. European Journal of Inorganic Chemistry 2017, 2017 (44), 5114-5120.

74. E. Glais, M. Pellerin, D. Alloyeau, N.Touati, B. Viana, C. Chanéac, submitted in sensors and actuators B, [2018]

75. (a) Gourier, D.; Bessière, A.; Sharma, S. K.; Binet, L.; Viana, B.; Basavaraju, N.; Priolkar, K. R., Origin of the visible light induced persistent luminescence of $\mathrm{Cr} 3+$-doped zinc gallate. Journal of Physics and Chemistry of Solids 2014, 75 (7), 826-837; (b) De Vos, A.; Lejaeghere, K.; Vanpoucke, D. E. P.; Joos, J. J.; Smet, P. F.; Hemelsoet, K., First-Principles Study of Antisite Defect Configurations in $\mathrm{ZnGa2O4:Cr}$ Persistent Phosphors. Inorganic Chemistry 2016, $55(5), 2402-2412$.

76. A. Feng, P.F. Smet, A Review of Mechanoluminescence in Inorganic Solids: Compounds, Mechanisms, Models and Applications, Materials 2018, 11(4), 484; doi:10.3390/ma1 1040484

77. Bos, A. J. J., Thermoluminescence as a Research Tool to Investigate Luminescence Mechanisms. Materials 2017, 10 (12).

78. Van den Eeckhout, K.; Bos, A. J. J.; Poelman, D.; Smet, P. F., Revealing trap depth distributions in persistent phosphors. Physical Review B 2013, 87 (4), 11. 79. J. T. Randall, M. H. F. Wilkins, Proc. R. Soc. A Math. Phys. Eng. Sci. (1945), 184 (999), 365-389

80. He, Q.; Zhang, Z.; Gao, F.; Li, Y.; Shi, J., In vivo Biodistribution and Urinary Excretion of Mesoporous Silica Nanoparticles: Effects of Particle Size and PEGylation. Small 2011, 7 (2), 271-280.

81. Lu, J.; Liong, M.; Li, Z.; Zink, J. I.; Tamanoi, F., Biocompatibility, Biodistribution, and Drug-Delivery Efficiency of Mesoporous Silica Nanoparticles for Cancer Therapy in Animals. Small 2010, 6 (16), 1794-1805.

82. Hudson, S. P.; Padera, R. F.; Langer, R.; Kohane, D. S., The biocompatibility of mesoporous silicates. Biomaterials 2008, 29 (30), 4045-4055.

83. Duncan, R.; Sat, Y. N., Tumour targeting by enhanced permeability and retention (EPR) effect. Annals of Oncology 1998, 9, 39-39. 
84. Katayama, Y.; Viana, B.; Gourier, D.; Xu, J.; Tanabe, S., Photostimulation induced persistent luminescence in Y 3 Al 2 Ga 3 O 12: Cr 3+. Optical Materials Express 2016, 6 (4), 1405-1413.

85. (a) Burbano, D. C. R.; Rodriguez, E. M.; Dorenbos, P.; Bettinelli, M.; Capobianco, J. A., The near-IR photo-stimulated luminescence of CaS:Eu2+/Dy3+ nanophosphors. Journal of Materials Chemistry C 2014, 2 (2), 228-231; (b) Zhuang, Y.; Ueda, J.; Tanabe, S., Photochromism and white long-lasting persistent luminescence in $\mathrm{Bi} 3+-$ doped $\mathrm{ZnGa} 2 \mathrm{O} 4$ ceramics. Optical Materials Express 2012, 2 (10), 1378-1383; (c) Zhuang, Y.; Ueda, J.; Tanabe, S., Tunable trap depth in $\mathrm{Zn}(\mathrm{Ga1}-\mathrm{xAlx})(2) \mathrm{O}-4$ :Cr,Bi red persistent phosphors: considerations of hightemperature persistent luminescence and photostimulated persistent luminescence. Journal of Materials Chemistry C 2013, 1 (47), 7849-7855.

86. Bowman, S. G. E.; Chen, R., SUPER-LINEAR FILLING OF TRAPS IN CRYSTALS DUE TO COMPETITION DURING IRRADIATION. Journal of Luminescence 1979, 18-9 (JAN), 345-348.

87. Sharma, S. K.; Gourier, D.; Teston, E.; Scherman, D.; Richard, C.; Viana, B., Persistent luminescence induced by near infra-red photostimulation in chromium-doped zinc gallate for in vivo optical imaging. Optical Materials 2017, $63,51-58$.

88. Liu, F.; Chen, Y.; Liang, Y.; Pan, Z., Phonon-assisted upconversion charging in $\mathrm{Zn} 3 \mathrm{Ga} 2 \mathrm{GeO} 8: \mathrm{Cr} 3+$ near-infrared persistent phosphor. Optics Letters 2016, 41 (5), 954-957.

89. Y. Chen, F. Liu, Y. Liang, X. Wang, J. Bi, X. Wang and Z. Pan, J. Mater. Chem. C, 2018, DOI: 10.1039/C8TC02419G

90. Liang, S.; Pei-Pei, L.; Wen, Y.; Xia-Hui, L.; Hong, L.; Xiao-Feng, C.; Gang, L.; Juan, L.; Huang-Hao, Y., Low-Dose X-ray Activation of W(VI)-Doped Persistent Luminescence Nanoparticles for Deep-Tissue Photodynamic Therapy. Advanced Functional Materials 2018, 28 (18), 1707496.

91. Naczynski, D. J.; Sun, C.; Tuerkcan, S.; Jenkins, C.; Koh, A. L.; Ikeda, D.; Pratx, G.; Xing, L., X-ray-Induced Shortwave Infrared Biomedical Imaging Using RareEarth Nanoprobes. Nano Letters 2015, 15 (1), 96-102.

92. Chen, H.; Moore, T.; Qi, B.; Colvin, D. C.; Jelen, E. K.; Hitchcock, D. A.; He, J.; Mefford, O. T.; Gore, J. C.; Alexis, F.; Anker, J. N., Monitoring pHTriggered Drug Release from Radioluminescent Nanocapsules with X-ray Excited Optical Luminescence. Acs Nano 2013, 7 (2), 1178-1187.

93. Chen, H.; Wang, G. D.; Chuang, Y.-J.; Zhen, Z.; Chen, X.; Biddinger, P.; Hao, Z.; Liu, F.; Shen, B.; Pan, Z.; Xie, J., Nanoscintillator-Mediated X-ray Inducible Photodynamic Therapy for In Vivo Cancer Treatment. Nano Letters 2015, 15 (4), 2249-2256.

94. Lee, D.-E.; Koo, H.; Sun, I.-C.; Ryu, J. H.; Kim, K.; Kwon, I. C., Multifunctional nanoparticles for multimodal imaging and theragnosis. Chemical Society Reviews 2012, 41 (7), 2656-2672.

95. Reddy, L. H.; Arias, J. L.; Nicolas, J.; Couvreur, P., Magnetic Nanoparticles: Design and Characterization, Toxicity and Biocompatibility, Pharmaceutical and Biomedical Applications. Chemical Reviews 2012, 112 (11), 5818-5878. 
96. Abdukayum, A.; Yang, C.-X.; Zhao, Q.; Chen, J.-T.; Dong, L.-X.; Yan, X.-P., Gadolinium Complexes Functionalized Persistent Luminescent Nanoparticles as a Multimodal Probe for Near-Infrared Luminescence and Magnetic Resonance Imaging in Vivo. Analytical Chemistry 2014, 86 (9), 40964101.

97. Teston, E.; Lalatonne, Y.; Elgrabli, D.; Autret, G.; Motte, L.; Gazeau, F.; Scherman, D.; Clement, O.; Richard, C.; Maldiney, T., Design, Properties, and In Vivo Behavior of Superparamagnetic Persistent Luminescence Nanohybrids. Small 2015, 11 (22), 2696-2704.

98. Tassa, C.; Shaw, S. Y.; Weissleder, R., Dextran-Coated Iron Oxide Nanoparticles: A Versatile Platform for Targeted Molecular Imaging, Molecular Diagnostics, and Therapy. Accounts of Chemical Research 2011, 44 (10), 842-852. 99. Fan, Z.; Fu, P. P.; Yu, H.; Ray, P. C., Theranostic nanomedicine for cancer detection and treatment. Journal of Food and Drug Analysis 2014, 22 (1), 3-17.

100. Zhang, Y.; Chan, H. F.; Leong, K. W., Advanced materials and processing for drug delivery: The past and the future. Advanced Drug Delivery Reviews 2013, 65 (1), 104-120.

101. Asefa, T.; Tao, Z., Biocompatibility of Mesoporous Silica Nanoparticles. Chemical Research in Toxicology 2012, 25 (11), 2265-2284.

102. Dai, W. B.; Lei, Y. F.; Ye, S.; Song, E. H.; Chen, Z.; Zhang, Q. Y., Mesoporous nanoparticles $\mathrm{Gd} 2 \mathrm{O} 3 @ \mathrm{mSiO}(2) / \mathrm{ZnGa}_{2} \mathrm{O}_{4}: \mathrm{Cr}^{3+}, \mathrm{Bi}^{3+}$ as multifunctional probes for bioimaging. Journal of Materials Chemistry B 2016, 4 (10), 1842-1852.

103. Lim, C.-K.; Heo, J.; Shin, S.; Jeong, K.; Seo, Y. H.; Jang, W.-D.; Park, C. R.; Park, S. Y.; Kim, S.; Kwon, I. C., Nanophotosensitizers toward advanced photodynamic therapy of Cancer. Cancer Letters 2013, 334 (2), 176-187.

104. Lovell, J. F.; Liu, T. W. B.; Chen, J.; Zheng, G., Activatable Photosensitizers for Imaging and Therapy. Chemical Reviews 2010, 110 (5), 28392857.

105. Wang, C.; Cheng, L.; Liu, Z., Upconversion Nanoparticles for Photodynamic Therapy and Other Cancer Therapeutics. Theranostics 2013, 3 (5), 317-330.

106. Oh, S. B.; Park, H. R.; Jang, Y. J.; Choi, S. Y.; Son, T. G.; Lee, J., Baicalein attenuates impaired hippocampal neurogenesis and the neurocognitive deficits induced by gamma-ray radiation. British Journal of Pharmacology 2013, 168 (2), 421-431.

107. Rothkamm, K.; Lobrich, M., Evidence for a lack of DNA double-strand break repair in human cells exposed to very low x-ray doses. Proceedings of the National Academy of Sciences of the United States of America 2003, 100 (9), 5057 5062.

108. Ramirez-Garcia, G.; Martinez-Alfaro, M.; d'Orlye, F.; Bedioui, F.; Mignet, N.; Varenne, A.; Gutierez-Granados, S.; Richard, C., Photo-stimulation of persistent luminescence nanoparticles enhances cancer cells death. International Journal of Pharmaceutics 2017, 532 (2), 696-703. 
109. Shanmugam, V.; Selvakumar, S.; Yeh, C.-S., Near-infrared lightresponsive nanomaterials in cancer therapeutics. Chemical Society Reviews 2014, 43 (17), 6254-6287.

110. Jaffray, D. A., Image-guided radiotherapy: from current concept to future perspectives. Nature Reviews Clinical Oncology 2012, 9 (12), 688-699.

111. Chen, H.; Zheng, B.; Liang, C.; Zhao, L.; Zhang, Y.; Pan, H.; Ji, W.; Gong, X.; Wang, H.; Chang, J., Near-infrared persistent luminescence phosphors ( $\mathrm{ZnGaO} 4)-\mathrm{O}-2: \mathrm{Cr} 3+$ as an accurately tracker to photothermal therapy in vivo for visual treatment. Materials Science \& Engineering C-Materials for Biological Applications 2017, 79, 372-381.

112. Liang, Y.; Liu, F.; Chen, Y.; Wang, X.; Sun, K.; Pan, Z., Extending the applications for lanthanide ions: efficient emitters in short-wave infrared persistent luminescence. Journal of Materials Chemistry C 2017, 5 (26), 6488-6492.

113. (a) Castaing, V.; Sontakke, A. D.; Xu, J.; Fernández-Carrión, A. J.; Allix, M.; Tanabe, S.; Viana, B. In Persistent luminescence in both first and second

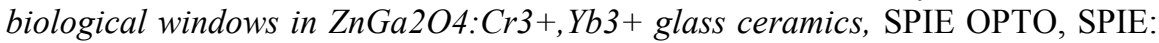
2018; p 7; (b) Xu, J.; Murata, D.; Katayama, Y.; Ueda, J.; Tanabe, S., Cr3+/Er3+ co-doped LaAlO3 perovskite phosphor: a near-infrared persistent luminescence probe covering the first and third biological windows. Journal of Materials Chemistry $B$ 2017, 5 (31), 6385-6393.

114. (a) Pellerin, M.; Castaing, V.; Gourier, D.; Chanéac, C.; Viana, B. In Persistent luminescence of transition metal (Co, Ni...)-doped ZnGa2O4 phosphors for applications in the near-infrared range, SPIE OPTO, SPIE: 2018; p 8; (b) Feng, L.; Yanjie, L.; Yafei, C.; Zhengwei, P., Divalent Nickel-Activated Gallate-Based Persistent Phosphors in the Short-Wave Infrared. Advanced Optical Materials 2016, 4 (4), 562-566.

115. Nie, J.; Li, Y.; Liu, S.; Chen, Q.; Xu, Q.; Qiu, J., Tunable long persistent luminescence in the second near-infrared window via crystal field control. Scientific Reports 2017, 7.

116. Xu, J.; Tanabe, S.; Sontakke, A. D.; Ueda, J., Near-infrared multiwavelengths long persistent luminescence of $\mathrm{Nd} 3+$ ion through persistent energy transfer in $\mathrm{Ce} 3+, \mathrm{Cr} 3+$ co-doped $\mathrm{Y} 3 \mathrm{~A} 12 \mathrm{Ga} 3 \mathrm{O} 12$ for the first and second bioimaging windows. Applied Physics Letters 2015, 107 (8).

117. Xu, J.; Murata, D.; Ueda, J.; Tanabe, S., Near-infrared long persistent luminescence of Er3+ in garnet for the third bio-imaging window. Journal of Materials Chemistry C 2016, 4 (47), 11096-11103.

118. A. M. Smith, M. C. Mancini, and S. Nie, Nature Nanotechnol.; 4(11), 710$711(2009)$

119. (a) Brites, C. D. S.; Lima, P. P.; Silva, N. J. O.; Millan, A.; Amaral, V. S.; Palacio, F.; Carlos, L. D., Thermometry at the nanoscale. Nanoscale 2012, 4 (16), 4799-4829; (b) Jaque, D.; Vetrone, F., Luminescence nanothermometry. Nanoscale 2012, 4 (15), 4301-4326; (c) Martin Rodriguez, E.; Lopez-Pena, G.; Montes, E.; Lifante, G.; Garcia Sole, J.; Jaque, D.; Armando Diaz-Torres, L.; Salas, P., Persistent luminescence nanothermometers. Applied Physics Letters 2017, 111 (8). 120. Ai, T.; Shang, W.; Yan, H.; Zeng, C.; Wang, K.; Gao, Y.; Guan, T.; Fang, C.; Tian, J., Near infrared-emitting persistent luminescent nanoparticles for 
Hepatocellular Carcinoma imaging and luminescence-guided surgery. Biomaterials 2018, 167, 216-225.

121. (a) Welsher, K.; Sherlock, S. P.; Dai, H., Deep-tissue anatomical imaging of mice using carbon nanotube fluorophores in the second near-infrared window. Proceedings of the National Academy of Sciences of the United States of America 2011, 108 (22), 8943-8948; (b) Bruns, O. T.; Bischof, T. S.; Harris, D. K.; Franke, D.; Shi, Y.; Riedemann, L.; Bartelt, A.; Jaworski, F. B.; Carr, J. A.; Rowlands, C. J.; Wilson, M. W. B.; Chen, O.; Wei, H.; Hwang, G. W.; Montana, D. M.; Coropceanu, I.; Achorn, O. B.; Kloepper, J.; Heeren, J.; So, P. T. C.; Fukumura, D.; Jensen, K. F.; Jain, R. K.; Bawendi, M. G., Next-generation in vivo optical imaging with short-wave infrared quantum dots. Nature Biomedical Engineering 2017, 1 (4); (c) He, S.; Song, J.; Qu, J.; Cheng, Z., Crucial breakthrough of second nearinfrared biological window fluorophores: design and synthesis toward multimodal imaging and theranostics. Chemical Society reviews 2018.

122. Hemmer, E.; Benayas, A.; Legare, F.; Vetrone, F., Exploiting the biological windows: current perspectives on fluorescent bioprobes emitting above 1000 nm. Nanoscale Horizons 2016, 1 (3), 168-184.

123. Hong, G.; Diao, S.; Chang, J.; Antaris, A. L.; Chen, C.; Zhang, B.; Zhao, S.; Atochin, D. N.; Huang, P. L.; Andreasson, K. I.; Kuo, C. J.; Dai, H., Throughskull fluorescence imaging of the brain in a new near-infrared window. Nature Photonics 2014, 8 (9), 723-730.

124. C. Boccara, Reflets OPhys. (2009), 13, 10-13

125. A. M. Smith, M. C. Mancini, and S. Nie, Nature Nanotechnol.; 4(11), 710 $711(2009)$ 


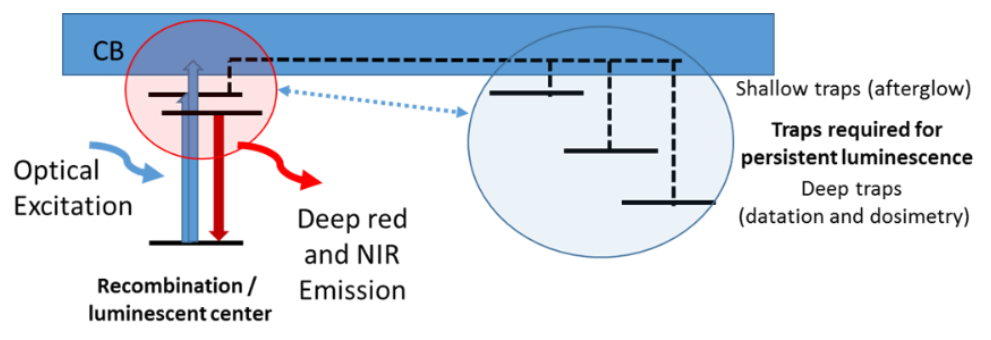

VB

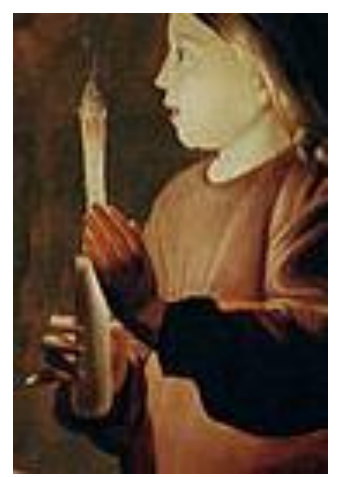

Fig. 1. Left: Schematic of the energy levels and traps involved in the persistent luminescence mechanisms. Right: Partial transparency of living tissues in deep red range (see light through girl left hand and figure $11(c)$ ), extracted from Saint Joseph charpentier, G. de La Tour, 1643, Musée du Louvres, Paris, France 

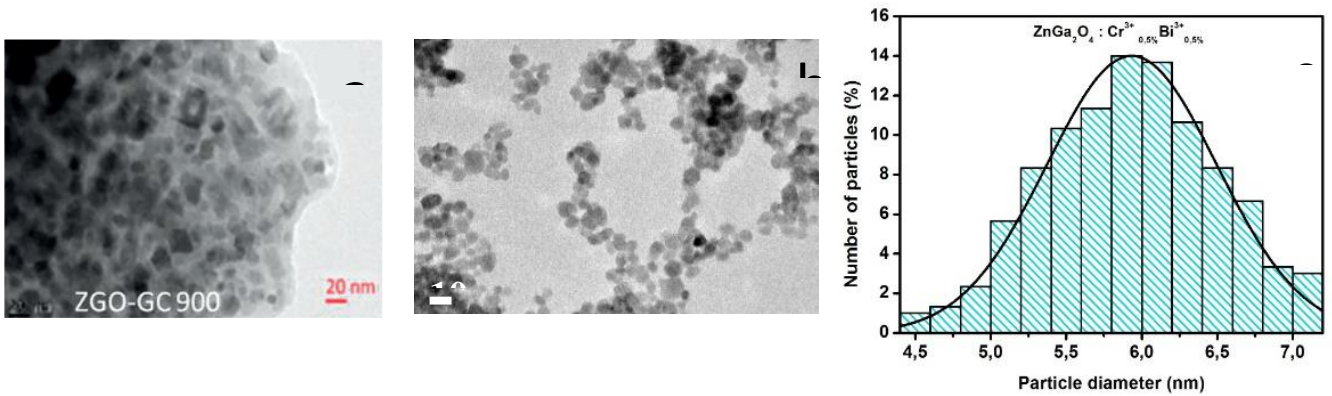

Fig. 2: TEM pictures of a) $\mathrm{ZnGa}_{2} \mathrm{O}_{4}: \mathrm{Cr}^{3+}(Z G O)$ nanoparticles embedded in glass matrix $\left(T C=900^{\circ} \mathrm{C}\right)$ b) ZGO nanoparticles after hydrothermal synthesis assisted by microwave heating, associated distribution diagram, adapted from E. Glais et al and V. Castaing et al. 

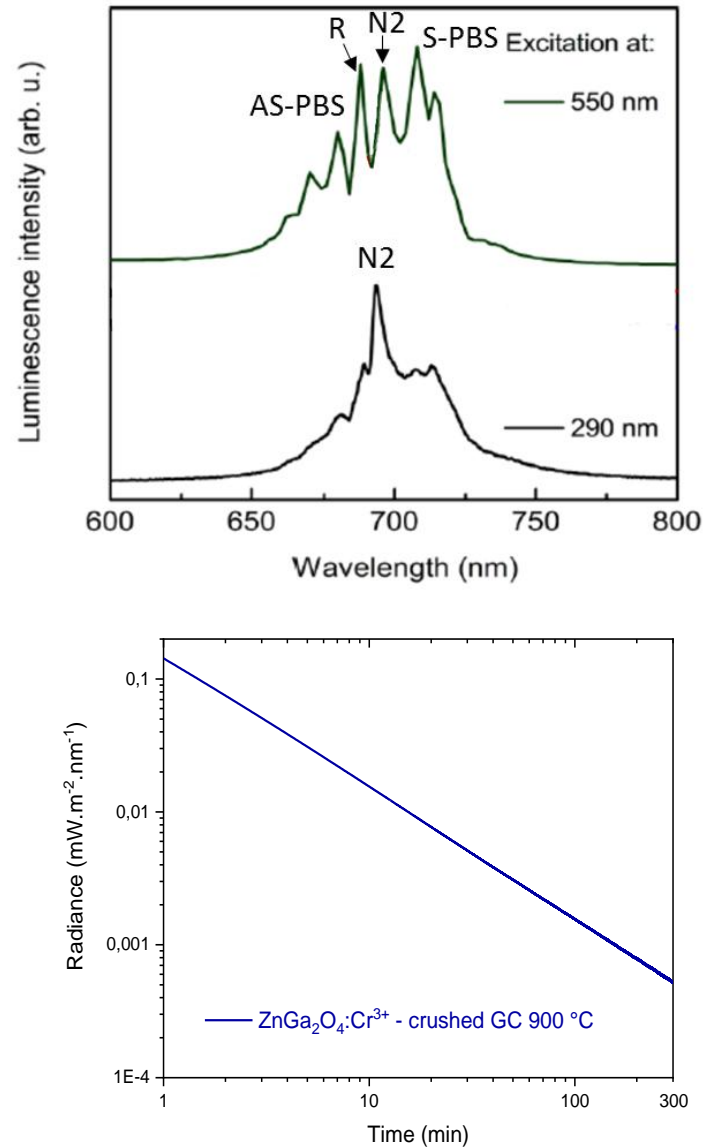

Fig. 3: Left, (top) Photoluminescence and (bottom) persistent luminescence spectrum at room temperature, adapted from Bessière et al [2011]. Right: Persistent luminescence decay of $\mathrm{ZnGa}_{2} \mathrm{O}_{4}: \mathrm{Cr}^{3+}$ Nanoparticules (within more than 2 hours) adapted from V. Castaing et al. 

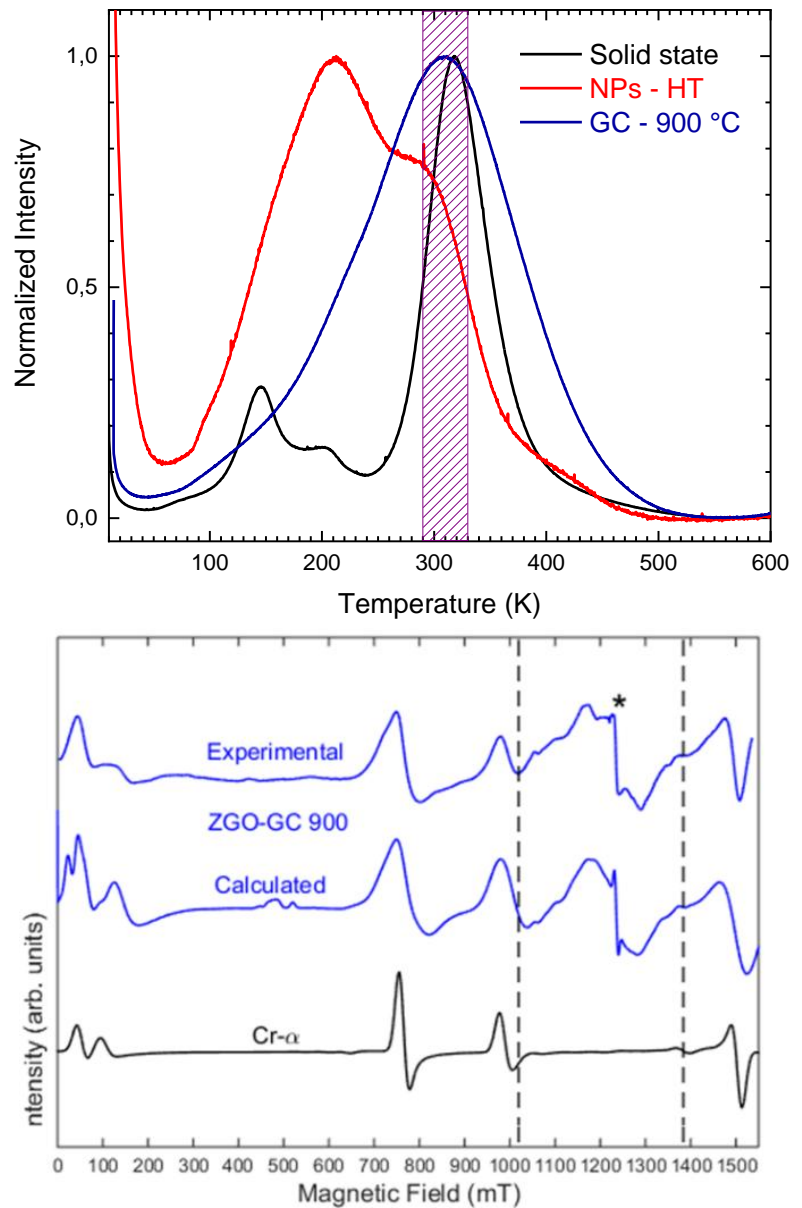

Fig. 4: Thermoluminescence glow curves with different sizes and shapes and right: Simulation and experimental EPR spectra for the ZGO:Cr extracted from V. Castaing et al. 


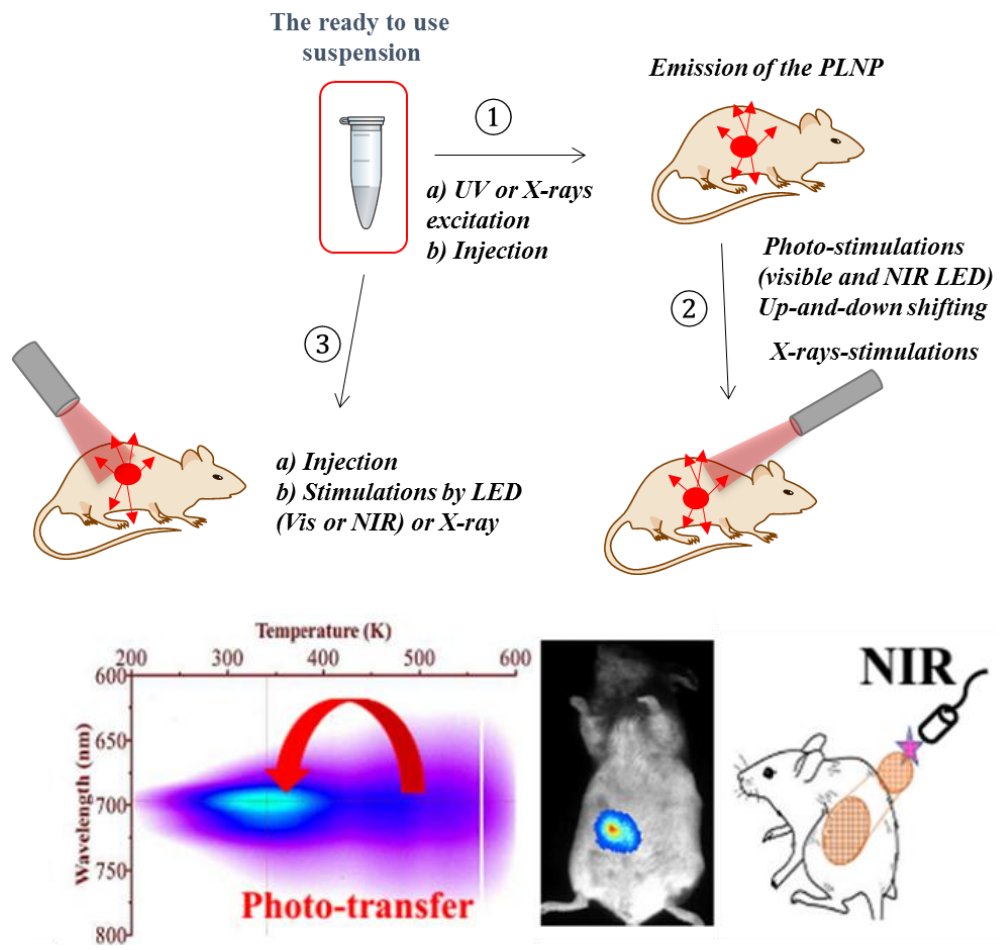

Fig 5: Top: different strategies to perform in vivo optical imaging with persistent luminescence nanoparticles (PLNP). (1) Excitation of a suspension of nanoparticles followed by tail vein injection and optical imaging using a photon counting camera. (2) Once the in vivo persistent luminescence signal has completely disappeared, some PLNP can give further persistent luminescence signal either by photo-or X-rays stimulations possibly giving $n$ decay signals. (3) Some PLNP can be excited without preliminary excitation (with lower efficiency) in the animal body using visible, near infrared-for upconversion- or X-rays photons, Bottom Traps could be emptied by a near infrared source (energy $\sim 1 \mathrm{eV}$ ) showing the crucial role of charge-storage to deep traps and photo-transfer to shallow traps leading to persistent luminescence. This demonstrated the photostimulation capability at convenience time. Within this experiment, one observed long-lasting phosphorescence under $977 \mathrm{~nm}$ light excitation ${ }^{87}$, making in vivo excitation of the spinels probes envisioned and possible long term imaging applications 


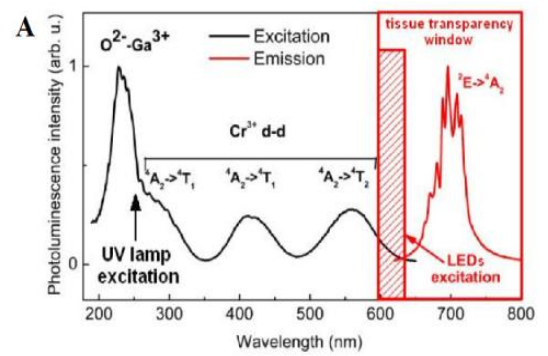

D

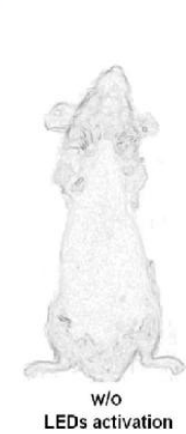

E

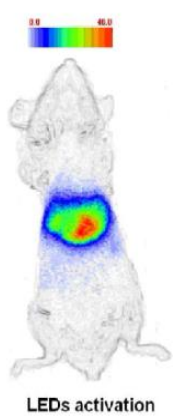

B

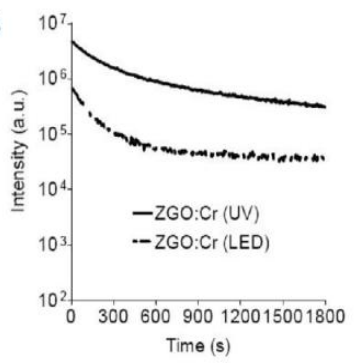

G

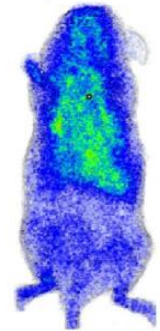

C

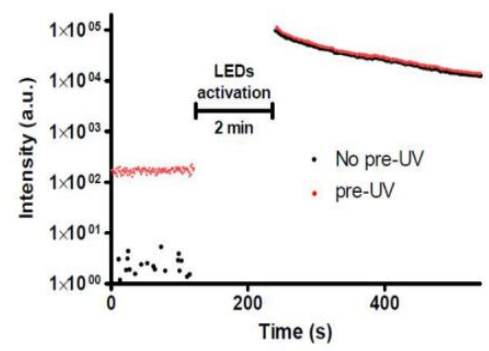

H

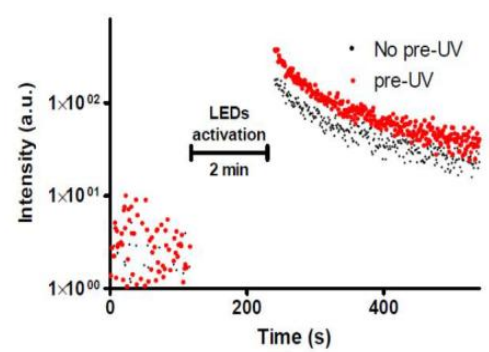

Fig. 6. In vivo imaging using in situ excitable PLNPs. (a-c) Optical properties of powder after either $U V$ or visible excitation. (d-h) In vivo excitation of un-functionalized PLNPs $(e)$ or stealth ZGO in healthy $(f)$ on tumor bearing mice ( $g$ ). 

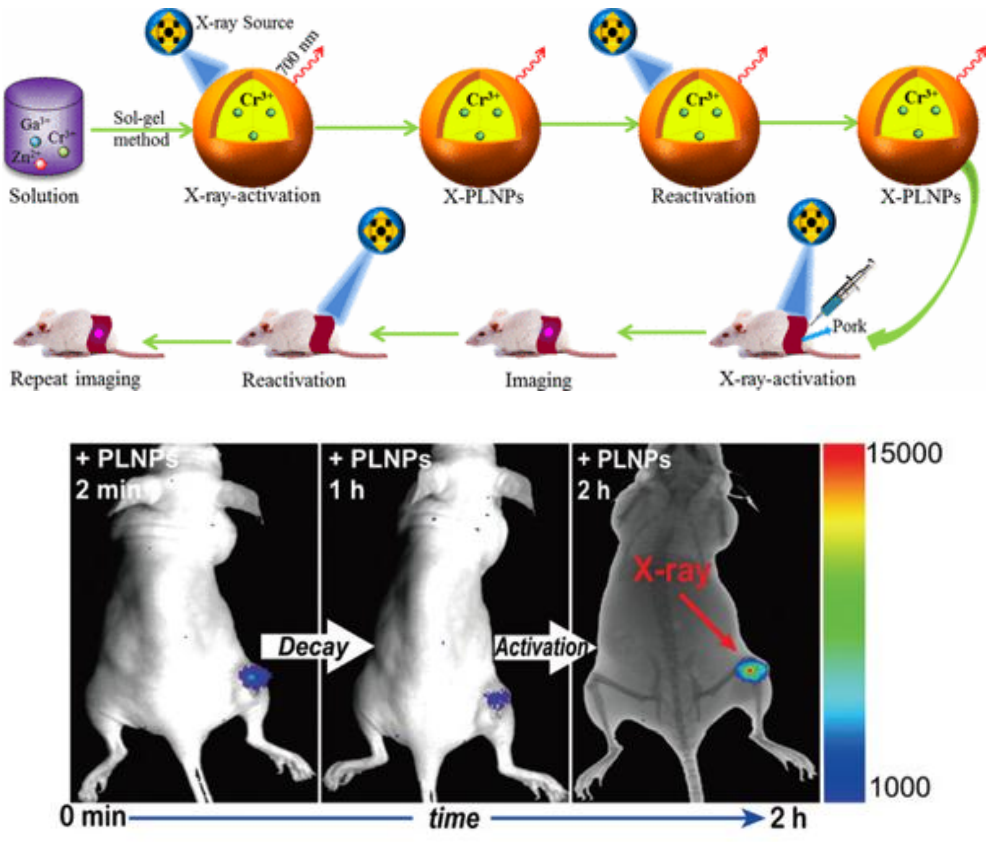

Fig. 7. (a) Principle of in vivo imaging using X-ray excitation. (b) Application in vivo, adapted from Xue et al. 


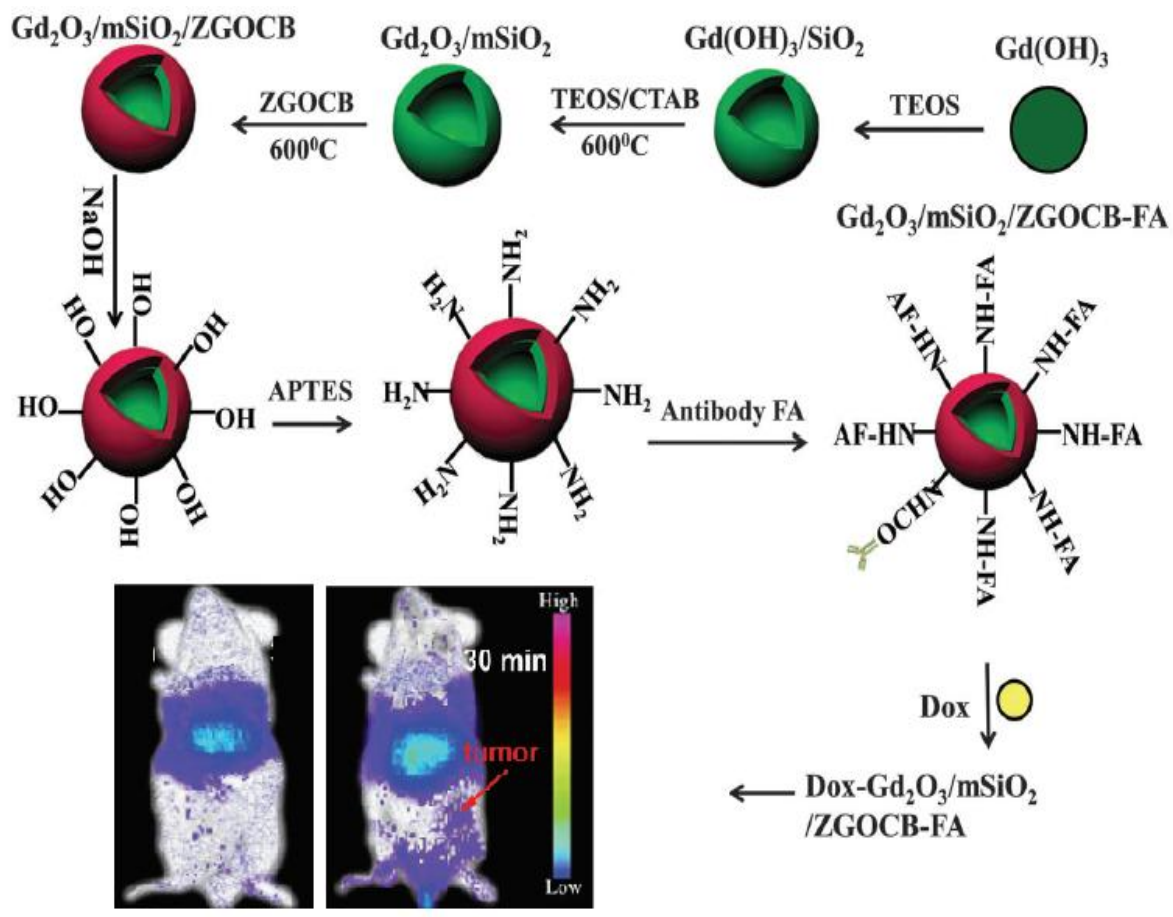

Fig. 8. Synthesis of mesoporous ZGO, loading with Dox and in vivo application, adapted from Dai et al. . 


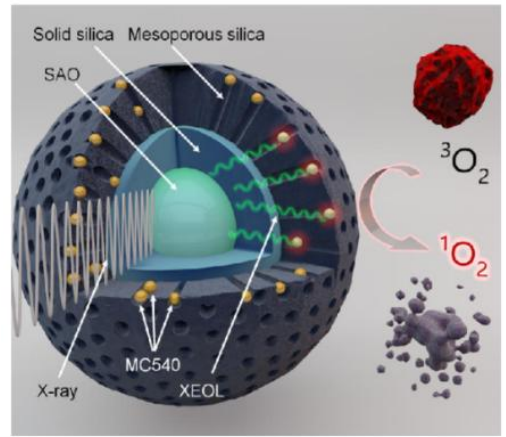

Fig. 9. Schematic of PLNPs loaded with PDT agent (MC540) adapted from Chen et al. . 


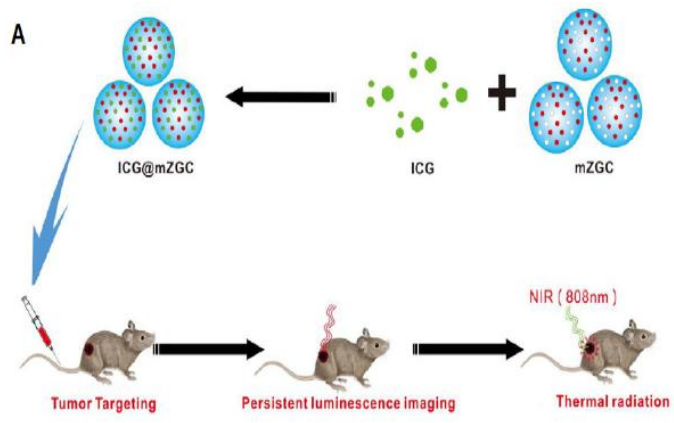

B

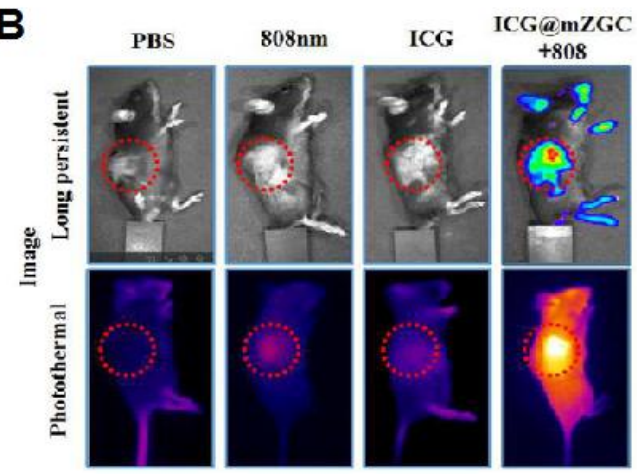

C

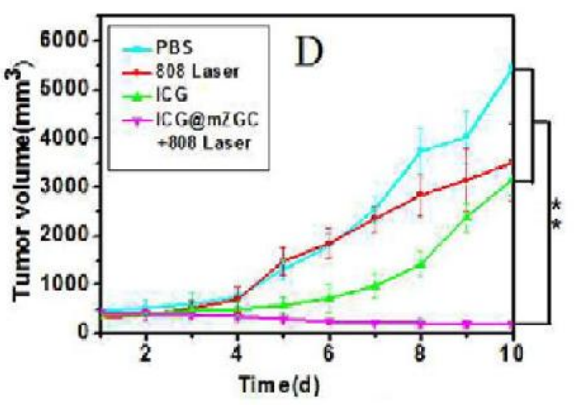

Fig. 10. PTT with ICG loaded PLNPs. Adapted from Chen at al. 


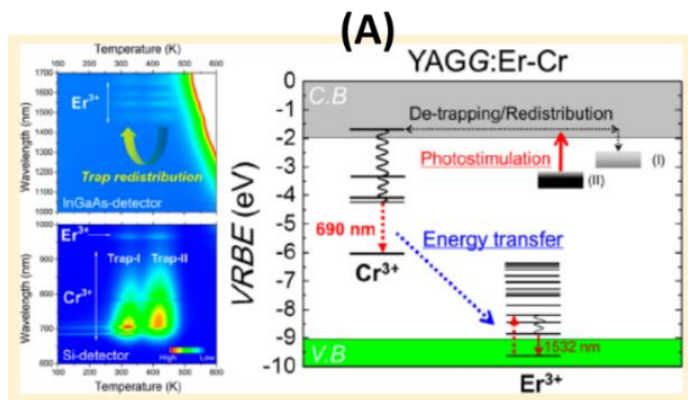

(B)

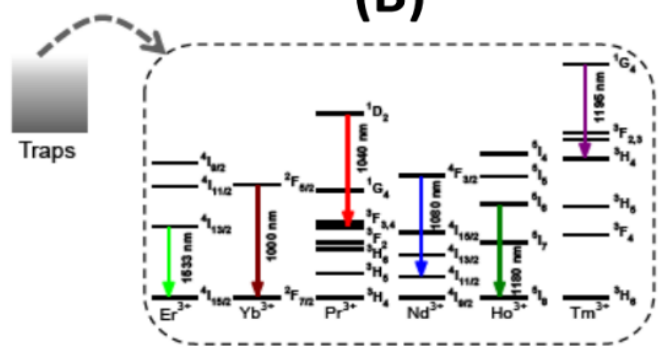

(C) $\underset{\text { BW-1 }}{\text { First Window }}$ BW-2 BW-3

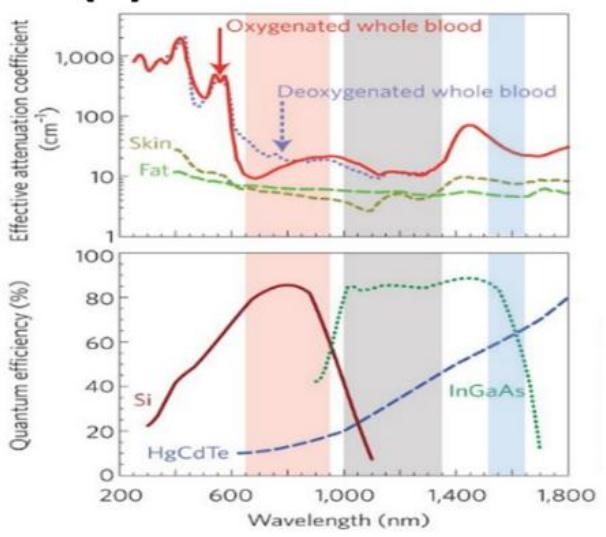




\section{(D)}

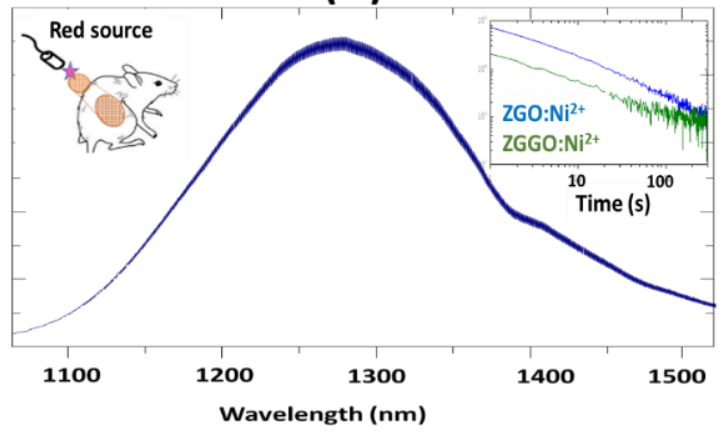

Fig. 11. : (A) trap redistribution and persistent energy transfer in metal transition $(\mathrm{Cr})$ and rare earth doped garnet ${ }^{47},(B)$ Trivalent rare earth cations as efficient emitters for short wave infrared persistent luminescence ${ }^{112}$, (C) Optical window in biological tissues; high: attenuation coefficient (log) as a function of the wavelength. Bottom: sensitivity of different cameras (silicon (Si) cameras, indium gallium arsenide (InGaAs) or mercury cadmium telluride $(\mathrm{HgCdTe}))^{125}$ and (D): optical features and persistent luminescence of $\mathrm{ZnGa}_{2} \mathrm{O}_{4}$ : $\mathrm{Ni}$ and $\mathrm{Zn}(\mathrm{GeGa})_{2} \mathrm{O}_{4}$ : Ni. Decay profiles and scheme of excitation ${ }^{114 a}$ 